\title{
The meninges as barriers and facilitators for the movement of fluid, cells and pathogens related to the rodent and human CNS
}

\author{
Roy O. Weller ${ }^{1} \cdot$ Matthew M. Sharp ${ }^{1} \cdot$ Myron Christodoulides $^{2} \cdot$ Roxana O. Carare $^{1} \cdot$ Kjeld Møllgård $^{3}$
}

Received: 5 November 2017 / Revised: 2 January 2018 / Accepted: 15 January 2018 / Published online: 24 January 2018

(C) The Author(s) 2018. This article is an open access publication

\begin{abstract}
Meninges that surround the CNS consist of an outer fibrous sheet of dura mater (pachymeninx) that is also the inner periosteum of the skull. Underlying the dura are the arachnoid and pia mater (leptomeninges) that form the boundaries of the subarachnoid space. In this review we (1) examine the development of leptomeninges and their role as barriers and facilitators in the foetal CNS. There are two separate CSF systems during early foetal life, inner CSF in the ventricles and outer CSF in the subarachnoid space. As the foramina of Magendi and Luschka develop, one continuous CSF system evolves. Due to the lack of arachnoid granulations during foetal life, it is most likely that CSF is eliminated by lymphatic drainage pathways passing through the cribriform plate and nasal submucosa. (2) We then review the fine structure of the adult human and rodent leptomeninges to establish their roles as barriers and facilitators for the movement of fluid, cells and pathogens. Leptomeningeal cells line CSF spaces, including arachnoid granulations and lymphatic drainage pathways, and separate elements of extracellular matrix from the CSF. The leptomeningeal lining facilitates the traffic of inflammatory cells within CSF but also allows attachment of bacteria such as Neisseria meningitidis and of tumour cells as CSF metastases. Single layers of leptomeningeal cells extend into the brain closely associated with the walls of arteries so that there are no perivascular spaces around arteries in the cerebral cortex. Perivascular spaces surrounding arteries in the white matter and basal ganglia relate to their two encompassing layers of leptomeninges. (3) Finally we examine the roles of ligands expressed by leptomeningeal cells for the attachment of inflammatory cells, bacteria and tumour cells as understanding these roles may aid the design of therapeutic strategies to manage developmental, autoimmune, infectious and neoplastic diseases relating to the CSF, the leptomeninges and the associated CNS.
\end{abstract}

Keywords Leptomeninges - CSF · Barriers and facilitators - Developing human and rat brain · Perivascular compartments and spaces · Attachment of Neisseria meningitidis, inflammatory cells and tumour cells to leptomeninges · Lymphatic drainage of the CNS

Roy O. Weller

row@soton.ac.uk

1 Clinical Neurosciences, South Academic Block, Level D, LD66, MP806, Faculty of Medicine University of Southampton, Southampton General Hospital, Southampton SO16 6YD, UK

2 Neisseria Research Laboratory, Molecular Microbiology, MP814, Academic Unit of Clinical and Experimental Sciences, Sir Henry Wellcome Laboratories, University of Southampton Faculty of Medicine, Southampton General Hospital, Southampton SO16 6YD, UK

3 Department of Cellular and Molecular Medicine, Faculty of Health and Medical Sciences, University of Copenhagen, Blegdamsvej 3, 2200 Copenhagen, Denmark

\section{Introduction}

The meninges covering the rodent and human CNS are divided primarily into the dura mater or pachymeninx and the arachnoid and pia mater or leptomeninges. Both dura and arachnoid encompass the brain and spinal cord and the arachnoid forms the outer barrier that contains CSF within the subarachnoid space (SAS). The pia is more closely applied to the brain and spinal cord but is separated from the CNS tissue on the surface of the CNS by a subpial space containing blood vessels and varying amounts of collagen.

For decades the meninges had been considered to be no more than a protective shield, but recent evidence suggests that leptomeninges have complex functions as barriers and facilitators for the movement of fluid, solutes and cells at 
the surface of the CNS and of fluid and solutes within the CNS parenchyma. Thus, the SAS functions as an important distribution system. The fundamental pattern of blood supply to the CNS is different from that of most other organs in which a single artery and accompanying veins penetrate the surface at a single point and divide into smaller and smaller branches within the organ. In the CNS, the arteries branch and divide into small muscular arteries and arterioles within the SAS prior to entering the brain and spinal cord, the surface of which is covered by a close network of numerous small vessels that enter and leave the CNS. The outer barriers of the brain function as morphogenetic signalling centres [27, 89], dynamic transport systems [108], a stem cell niche [27] and regulators of immune cell entry into the CNS [93] as summarised by Brøchner et al. [14].

The adult CNS is separated from peripheral tissues by a set of structures and physiological mechanisms that are present at various interfaces between the CNS parenchyma and surrounding fluids. Five main interfaces can be identified in the adult brain: (a) the arachnoid barrier, (b) the blood-brain barrier, (c) the blood-CSF barrier, (d) circumventricular organs (CVO) barrier formed by tight junctions between adjacent tanycytes, (e) the inner interface between the CSF and the brain (glia limitans) in the adult. An additional sixth interface, (f) the interface between the CSF and the embryonic brain is present only in the foetus $[62,83]$. In the adult, an arachnoid blood-CSF barrier separates the fenestrated blood vessels in the dura from the CSF in the SAS by means of a cell layer joined by tight junctions (the arachnoid barrier layer) [65]. Since the arachnoid blood-CSF barrier is avascular and provides a relatively small surface area, it is generally considered that it does not contribute significantly to blood-brain exchange [1]. However in light of recent findings of drug transporters and drug-metabolising enzymes in the arachnoid blood-CSF barrier [108] and taking into account that the arachnoid barrier cell layer constitutes a much larger fraction of the brain surface area during early development, it is clear that the arachnoid blood-CSF barrier is an important and changing interface that should not be ignored. It clearly warrants further investigation in the developing and adult brain.

In this review, we first examine the involvement of the leptomeninges in the development of the human and rat brains. We then review the structure of the adult leptomeninges to establish the interrelations between leptomeninges, CSF, blood vessels and the CNS parenchyma. The human CNS is much larger than the rodent CNS and the anatomical arrangements between the leptomeninges, blood vessels and CNS parenchyma are much easier to discern in the human CNS than in rodents. We will therefore define the major structural attributes of the human leptomeninges and compare them with rodent leptomeninges. This is an important aspect of the review as the majority of experimental studies examining the relationships between inflammatory cells and leptomeninges are performed in mice and how these studies relate directly to the human leptomeninges needs to be clearly defined. Although many investigations of the leptomeninges are performed through the medium of immunocytochemistry, ultrastructural studies form a valuable contribution to our understanding of the exact relationships between the delicate cell layers of leptomeninges and other structures within the human CNS. For this reason, we illustrate the structure of the adult human leptomeninges largely by their ultrastructure.

Barrier functions of the leptomeninges constitute an emerging field of research in both human and rodent CNS and are discussed in this review. However, just as important to the biology and pathology of the CNS is the role of leptomeninges as facilitators for the movement of fluid, solutes and inflammatory cells in relation to the CNS and it diseases. Leptomeninges as facilitators for attachment and movement of cells are also important in infections and tumour metastases in the SAS. We will review the attachment of bacteria to leptomeningeal cells, especially with regard to Neisseria meningitidis, and the role that leptomeningeal elements may play in the location and spread of tumour metastases within the SAS. Although in its early stages, the identification of ligands on the surfaces of leptomeningeal cells to which bacteria and tumour cells attach has clear implications for therapies in these and other disorders involving the leptomeninges.

As often occurs in fields undergoing active investigation, misconceptions have arisen and are perpetuated within the literature in relation to the leptomeninges and to the exchange and drainage of fluid associated with the CNS. For example, it has been assumed, perhaps wrongly, that the SAS is lined by collagen, that there are perivascular spaces for the entry of CSF into the brain and for the drainage of interstitial fluid (ISF) from the brain. Furthermore, the concept of the CSF as a sink for the drainage of ISF from the brain may need to be re-examined, particularly as the best estimate is that $85 \%$ of ISF from the brain drains to lymph nodes and only $15 \%$ of ISF passes into the CSF under normal conditions [94]. These experiments were performed in the rat using radioiodinated serum albumin. Injections into the caudate nucleus and internal capsule resulted in $10-15 \%$ of tracer passing into CSF. Injections into the much smaller midbrain resulted in $60-75 \%$ efflux of tracer into the CSF which was probably due to direct efflux following injection into the very small midbrain. The probability of direct efflux of tracer into the CSF following injection into the brain through too large a needle in too great a volume was identified by Carare et al. [17]. 


\section{Meninges in the developing human and rat brains}

Features of outer brain barrier and meningeal development in human and rat are summarised in Table 1 [14] (from Brøchner et al. [14]).

\section{Human brain and meninges}

In early foetal life, there are two separate CSF systems: inner CSF in the future cerebral ventricles and outer CSF in the future SAS. Following the development of the midline foramen of Magendi and the lateral foramina of Luschka, there is one continuous CSF system. However, during foetal life, CSF is not likely to drain through arachnoid granulations as they are not present prior to 39 weeks gestation [36]. They appear in greater number as children age and are clearly visible by 2 years and then increase further in size and number with increasing age [61]. Thus, it is likely that CSF at least in the neonatal brain is eliminated by lymphatic drainage pathways passing through the nasal submucosa [61].

By 5 weeks post-conception (wpc), the neural tube has closed around a fluid-filled neural cavity, initially filled with amniotic fluid but progressively modified and referred to as eCSF (embryonic cerebrospinal fluid) or the inner CSF. Closure of the neural tube occurs before the appearance of the choroid plexuses but also at a time when vascularisation of the brain tissue has barely begun. The first barriers or interfaces for exchange that develop in and around the embryonic brain are: (1) between the brain and inner CSF (eCSF) entrapped following closure of the neural tube; this occurs in humans 26 days post-conception (dpc) and (2) between the brain and loose vascular mesenchyme that is derived from the neural crest and forms the primary meninx at the outer surface of the brain anlage. There is no trace of a SAS at this time, just a primary meninx (meninx primitiva). Even when the SAS starts to develop, the origin of the fluid it contains is unclear. The fluid does not originate from the

Table 1 Features of outer brain barrier and meningeal development (from Brøchner et al. [14])

\begin{tabular}{|c|c|c|c|}
\hline Weeks post-conception & Feature & Species & References \\
\hline \multirow[t]{2}{*}{ 6th } & $\begin{array}{l}\text { Appearance of a primary meninx around most parts of } \\
\text { the brain }\end{array}$ & Human & O’Rahilly and Müller [70] \\
\hline & $\begin{array}{l}\text { Amoeboid microglial cells penetrate the brain by cross- } \\
\text { ing the pial basement membrane }\end{array}$ & Human & Verney et al. [100] \\
\hline \multirow[t]{2}{*}{7 th } & The skeletogenous layer becomes visible & Human & O’Rahilly and Müller [70] \\
\hline & $\begin{array}{l}\text { Differentiation of a leptomeningeal meshwork that is } \\
\text { presumed to contain liquid and represent the future } \\
\text { SAS }\end{array}$ & Human & O’Rahilly and Müller [70] \\
\hline \multirow[t]{3}{*}{ 8th } & $\begin{array}{l}\text { The dural limiting layer is almost complete in hind- } \\
\text { brain and midbrain but only present in the area } \\
\text { adjacent to the lateral fossa in the forebrain }\end{array}$ & Human & O’Rahilly and Müller [70] \\
\hline & $\begin{array}{l}\text { The fenestrated sinusoids of the pia-arachnoid become } \\
\text { non-fenestrated (E14) }\end{array}$ & Rat (E14) & Balslev et al. [10] \\
\hline & Most of the cisternae of the adult are already present & Human & O’Rahilly and Müller [70] \\
\hline 7th-10th & $\begin{array}{l}\text { Initial communication between the ventricular and } \\
\text { subarachnoid compartments }\end{array}$ & Human and rat (E17) & Brocklehurst [15], Johansson et al. [49] \\
\hline 11 th & $\begin{array}{l}\text { Completion of the subpial end feet layer (E16) and } \\
\text { claudin-11 positive arachnoid blood-CSF barrier } \\
\text { (E18) and thereby appearance of a clearly defined } \\
\text { SAS }\end{array}$ & Rat (E16 and E18) & Balslev et al. [10] \\
\hline 12 th-13th & $\begin{array}{l}\text { Second wave of microglial cells penetrate the brain via } \\
\text { the BBB and inner CSF-brain barrier }\end{array}$ & Human & Verney et al. [100] \\
\hline 12 (13th-15th) & Radial glial cells begin to transform into astrocytes & $\begin{array}{l}\text { Rhesus monkey } \\
\text { (E64) and newborn } \\
\text { ferret }\end{array}$ & Schmechel and Rakic [86]; Voigt [101] \\
\hline 25th-28th & Transition from subpial end feet layer to glia limitans & Human & Kadhim et al. [50] \\
\hline
\end{tabular}

The meninges and outer brain barriers form during embryogenesis and early foetal life. Many factors are involved in this dynamic process and are necessary for adequate development of the brain. O'Rahilly and Müller [70] described the development of the human meninges in 1986 according to Carnegie stages, but have recently revised this staging model [71]. This Table is a summary of important events in the development of the human meninges and the barrier between the outer CSF and the brain approximated to weeks post-conception (wpc). Results in Carnegie stages have been translated according to the revision by O'Rahilly and Müller [71] and from mammals to human according to the work of Clancy et al. [22]

E14 etc. embryonic day 14, SAS subarachnoid space 

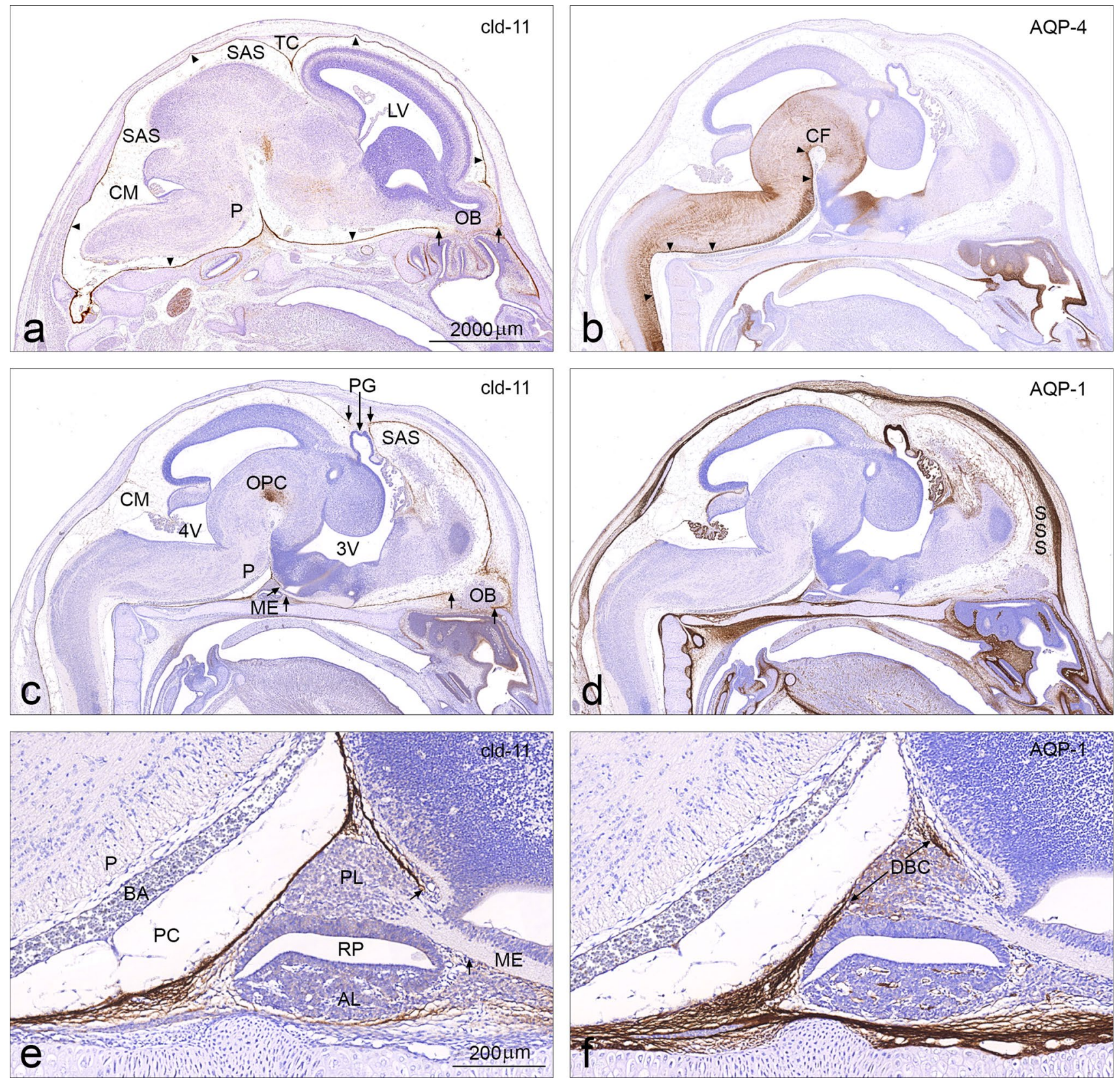

choroid plexus as this has not yet developed. Even when the choroid plexus has developed, CSF is secreted into a closed ventricular system that has no connection with the SAS. There are probably two separate CSF spaces until 10 wpc in humans and E17 in the rat (Table 1). The outer CSF space is the future SAS and the inner CSF spaces are the future ventricles. At this stage of development, the forebrain is still devoid of vasculature [62].

\section{Vascularisation}

In the early stages of vascularisation of the brain, a loose vascular ectomesenchyme, derived from the neural crest,

develops rostral to the mesencephalon and continues caudally along the brain stem and spinal cord as a vascular mesenchyme originating from the paraxial mesoderm. This layer of loose mesenchymal tissue, that surrounds the neural tube and the developing early brain anlage, has been termed the primary meninx [70]. Prior to the development of the dura and the leptomeninges (arachnoid, SAS and pia) an extensive microvascular network of interdigitating small arterioles, capillaries and venules, termed the perineural vascular plexus (PNVP), is established by vasculogenesis at the surface of the neural tissue. Following differentiation of the leptomeninges from 7 to $10 \mathrm{wpc}$, the PNVP will form 
4Fig. 1 Immunocytochemistry of the leptomeninges in the developing rat brain at low magnification. a-d Sagittal sections from an E18 rat brain at low magnification demonstrating the arachnoid barrier cell layer stained for claudin 11 (a, c), together with dural border cells and dura stained for AQP1 (d). b In contrast to the meninges that are immunonegative for AQP4, the astrocyte end feet layer of the entire ventral surface of the brain stem up to the cephalic flexure (CF) is strongly immunopositive for AQP4 (arrowheads). a Parasagittal section at the level of the olfactory bulb $(\mathrm{OB})$ depicting the discontinuity ('the olfactory bulb hole') (between arrows) in the arachnoid barrier cell layer indicated by arrowheads. b-d Consecutive near-midsagittal sections through the developing pineal gland (PG), third ventricle $(3 \mathrm{~V})$ and median eminence (ME) and superior sagittal sinus (SSS) in $\mathbf{d}$. Note the discontinuities in the barrier cell layer between double arrows corresponding to the pineal gland ('the peripineal slit') and the median eminence ('the peripituitary slit') which is visible at higher magnification in e. The caudal part of the peripineal slit can be recognised even at low magnification between the central small and the larger arrow pointing to the pineal gland diverticulum. Higher magnifications of the cisterna magna $(\mathrm{CM})$ and the subarachnoid space (SAS) in relation to the choroid plexus and brain surface are shown in Fig. 2. Note the dense group of oligodendrocyte progenitor cells (OPC) facing the cephalic flexure in c. e, f At higher magnification the meninges and their relationship to the pontine cistern (PC) and the primordium of the pituitary gland, including the posterior lobe (PL), Rathke's pouch (RP) and the anterior lobe (AL) are depicted. The ventral surface of the pons $(\mathrm{P})$ and the basilar artery (BA) are not stained either for claudin-11 or AQP-1. The posterior lobe is separated from the cisterns of the subarachnoid space by a claudin-11-positive arachnoid barrier cell layer which terminates abruptly (small arrows) where the neurohypophysis emerges from the median eminence (ME). Note the strong AQP-1 immunoreactivity of the dural border cells (DBC) in f. $3 V$ third ventricle, $4 V$ fourth ventricle, $A L$ anterior lobe, $A Q P-1$ aquaporin-1, $A Q P-4$ aquaporin-4, $B A$ basilar artery, cld-11 claudin- $11, C F$ cephalic flexure, $C M$ cisterna magna, $D B C$ dural border cells, $L V$ lateral ventricle, $M E$ median eminence, $O B$ olfactory bulb, $O P C$ oligodendrocyte progenitor cells, $P$ pons, $P C$ pontine cistern, $P G$ pineal gland diverticulum, $P L$ posterior lobe, RP Rathke's pouch, SAS subarachnoid space, SSS superior sagittal sinus, $T C$ tentorium cerebelli. a-d Same magnification. Scale bar $2000 \mu \mathrm{m}$. e-f Same magnification. Scale bar $200 \mu \mathrm{m}$

a very dense leptomeningeal vascular plexus, the vascular distribution system, in the SAS [62].

\section{Development of barriers in the brain}

There is a clear distinction in the pattern of development between blood-brain and blood-CSF barriers and the complex arachnoid barrier. In a recent paper, it was shown by claudin-11 immunolabelling that the interfaces associated with the human arachnoid barrier layer develop over a prolonged period of 5 weeks - from $7 \mathrm{wpc}$ to $12 \mathrm{wpc}$-before there is a well delineated and, thus well-defined, subarachnoid space [62]. The barrier layer appears first in the posterior cranial fossa from where it extends rostrally towards the olfactory bulbs, initially covering the base of the skull from where it spreads towards the vertex (for a more detailed description, see [62]). This process, which is completed by the 12 th wpc in humans corresponds to embryonic day 18
(E18) in the rat (see Table 1) from which a number of new findings will be presented in the next section.

The interface between the outer CSF and the brain restricts diffusion between brain and subarachnoid CSF through an initial layer of radial glial end feet covered by a surface layer of pia and, in the third trimester, by glia limitans covered with a surface layer of pia [14]. Complex barriers at the surface of the brain, particularly during development, are poorly defined [10], but by mid-gestation subarachnoid interfaces are almost fully developed. The SAS is delineated by the arachnoid barrier cell layer adjacent to the dura and the astrocyte end feet layer on the surface of the brain forming two individual interfaces: (1) the arachnoid forming a barrier or interface between the blood vessels in the dura and the outer CSF in the SAS and (2) the interface between the outer CSF and the surface of the brain. In addition there is a third interface within the SAS between the outer CSF and the blood in the pial microvasculature [14]. The vasculature in the SAS is characterised from earliest development by claudin-5 positive tight junctions in endothelial cells that confer its barrier properties as confirmed by the exclusion of plasma proteins, e.g. AFP [62].

\section{Meninges and claudin-11 in the developing rat brain}

The tight junction protein, claudin-11, was initially described as the basis for the blood-testes barrier (Sertoli cell tight junctions) and shown to be the same as oligodendrocyte specific protein (OSP) responsible for the tight junctions between oligodendrocytic myelin sheaths and axons [63]. Later, the developing arachnoid barrier cell layer was shown to be immunoreactive for claudin-11 in humans and in rats from E18 [14] and also in the E16 mouse [105]. The arachnoid is thus the barrier between the outer CSF in the SAS and the fenestrated blood vessels in the dura.

The general morphogenesis of cranial meninges in the rat was described by Angelov and Vasilev [6] at a time when claudin-11 as a marker for arachnoid barrier cells had not yet been identified. More recently it has been demonstrated that the early rat brain (E10-E14) shows no signs of claudin-11 immunoreactivity, but that at E15, weak staining is present in the loosely packed arachnoid barrier cells at the base of the brain and extending into the future tentorium cerebelli [14]. In the following description we summarise some new immunohistochemical findings from the stage in rat brain development (E18) in which a well-defined SAS is first present.

A large number of sagittal sections from the E18 rat were stained for claudin-11 to ensure that there is a complete arachnoid barrier between the outer CSF and the fenestrated blood vessels in the dura, apart from the known openings where the cranial nerves perforate the dura-arachnoid (see Fig. 1A in Ref. [14]). Due to the interest in CSF flow, adjacent sections 
were stained for aquaporin-1 and -4 (AQP-1 and AQP-4). Parasagittal sections at the level of the olfactory bulb demonstrate a consistently large disruption in the arachnoid barrier layer overlying the cribriform plate ('the olfactory bulb hole') providing free access for drainage of CSF to the nasal submucosa (Fig. 1a). Even in other midsagittal sections 'the olfactory bulb hole' is still present but now accompanied by discontinuities in the arachnoid barrier corresponding to the median eminence (the peripituitary slit') and the pineal gland ('the peripineal slit') (Fig. 1c). Not only CSF but also blood cells belonging to the immune system could well pass into the SAS at this location.

Dura, including dural border cells, are immunoreactive for AQP-1 (Fig. 1d) but not for AQP-4 which stains the astrocyte end feet layer of the entire ventral surface of the brain stem (Fig. 1b). The arachnoid barrier cell layer covering the posterior lobe of the pituitary is not positive for AQP-1 in contrast to the AQP-1 positive subdural border cells which are not stained for claudin-11 (compare Fig. 1e, f).

At higher magnification, strong claudin-11 immunoreactivity extends from the arachnoid barrier cell layer via arachnoid trabeculae towards the tela choroidea to cover the base of the stroma of the choroid plexus in both fourth and third ventricles (Fig. 2a, c). These findings are important in discussions about the continuity of the SAS and pial tissues with the stroma of the choroid plexus [107] and the so-called functional leak at the tela choroidea between ependyma and choroid plexus epithelium [13]. The claudin-11 positive pial cells within the stroma of the choroid plexus could well act as a narrow barrier layer between the blood and CSF in the SAS.

In addition to the AQP-1 immunoreactivity in dural border cells, choroid plexus epithelium and the external granular layer of the cerebellum, the leptomeningeal vascular plexus in the SAS covering the dorsal brain stem (Fig. 2b) and cortex (Fig. 2d) are clearly positively stained. These pial microvessels are also strongly immunoreactive for claudin-5 (Fig. 2e) in parallel with early human perineural and leptomeningeal blood vessels. Influx transporters-here exemplified by the excitatory amino acid transporter-1 (EAAT-1) - are also present in the arachnoid barrier cell layer (arrowheads in Fig. 2f). Materials and methods are described in Brøchner et al. [14].

\section{Meninges associated with the adult human brain}

\section{Dura mater}

The cranial dura in humans is approximately $1 \mathrm{~mm}$ thick; it is composed of dense fibrous tissue and forms the inner periosteum of the skull. Sheets of dura, the falx cerebri and tentorium cerebelli divide the cranial cavity into three major compartments. In children, the dura adheres firmly to the sutures of the skull but, as the sutures close in young adults, the dura can be easily stripped from the inside of the skull; with advancing age, the dura adheres more firmly to the inner aspect of the skull. Much of the blood supply for the dura is derived from the middle meningeal branches of the maxillary artery and other arteries derived from the external carotid and from branches of the occipital and vertebral arteries in the posterior fossa. Microscopically the dura consists of densely packed bundles of collagen fibres with interspersed arteries, veins and lymphatics. There is no barrier comparable to the blood-brain barrier associated with blood vessels in the dura. Major venous sinuses draining blood from the brain are enclosed within the cranial dura and dural lymphatics contribute to the drainage of CSF from the SAS $[8,54,59]$. As no direct connections between the brain and dural lymphatics have been established, it is unlikely that fluid and solutes from the brain drain into dural lymphatics.

Arachnoid separates easily from the inner aspect of the dura over most of the surface of the cerebral hemispheres in humans during surgical operations and at post-mortem. The only regions of adherence are where cortical veins join venous sinuses in the dura and where a small number of vascular bundles containing arteries and veins cross the subarachnoid and subdural spaces from the surface of the brain to the dura [11]. Such vascular bundles are mainly in the temporal regions and in the posterior fossa. Arteriovenous malformations in the dura have a significant effect on the vasculature of the brain through these connections and may be associated with cerebral venous thrombosis or intracranial haemorrhage [82].

In the spinal column, the dura forms a tube around the outer layer of arachnoid and, in humans, is separated from the bones of the vertebral column by epidural adipose tissue and venous plexuses. There is a series of dentate ligaments along the length of the human spinal cord that connect the dura to the substantial layer of subpial collagen encompassing the human spinal cord [68]; the dentate ligaments appear to stabilise the cord within the spinal SAS.

Both the cranial and spinal dura in rodents are much thinner than in humans and are often best examined histologically within the intact skull [23]. As in humans, the rodent dura is composed of bundles of collagen fibres and also contains arteries, veins and lymphatics $[8,54,59]$.

\section{Leptomeninges}

\section{General features of leptomeningeal cells}

Leptomeningeal cells show variable ultrastructural and immunocytochemical characteristics depending upon the structures with which they are associated [4]. Intercellular junctions include tight junctions in the barrier layer of arachnoid where it abuts the dura and desmosomes in the 

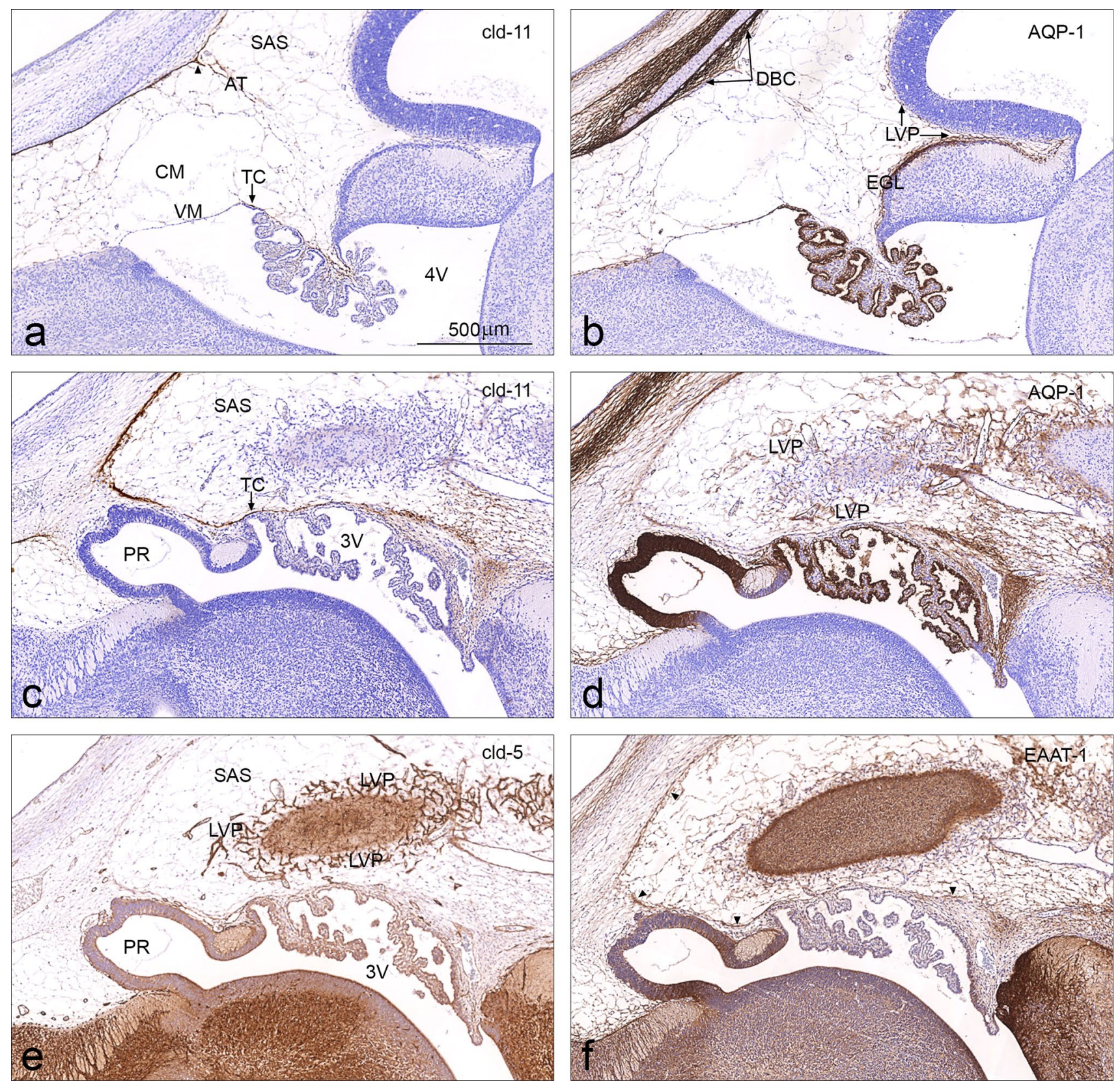

Fig. 2 Immunocytochemistry of the leptomeninges in the developing rat brain at higher magnification. a-f Higher magnification of $\mathbf{c}$, d of Fig. 1a-d and two more consecutive sections stained for claudin-5 (e) and EAAT-1 (f). The claudin-11 immunoreactivity extends from the arachnoid barrier cell layer via some arachnoid trabecular cells (AT) towards the tela choroidea (TC) to cover the base of the stroma of the choroid plexus in the fourth and third ventricles (4V and $3 \mathrm{~V})$. The roof of the fourth ventricle, velum medullare (VM), is not reacting. Dural border cells (DBC), choroid plexus epithelium, external granular layer of the cerebellum (EGL) and the dense leptomeningeal vascular plexus (LVP) covering the dorsal surface of the brain are stained for AQP-1. In e the dense leptomeningeal vascular plexus (LVP) in the subarachnoid space facing the dorsal brain sur-

face in a tangential section is strongly stained for claudin-5 (cld-5). $\mathbf{f}$ The immunoreactivity of the arachnoid barrier cell layer stained for influx transporter EAAT-1 (arrowheads). Note the similarity between the claudin-11 staining in c, e.g. next to the tela choroidea (TC), with that of the EAAT-1 staining but in contrast to the lack of AQP-1 reactivity in $\mathbf{d}$ thus supporting the specificity of the immunoreactions. $3 \mathrm{~V}$ third ventricle, $4 V$ fourth ventricle; $A Q P-1$ aquaporin-1, $A Q P-4$ aquaporin-4, $A T$ arachnoid trabecular cells; cld-5 claudin-5, cld-11 claudin-11, $C M$ Cisterna magna, $D B C$ dural border cells, EAAT-1 excitatory amino acid transporter-1, $P G$ pineal gland diverticulum, $P R$ pineal recess, $S A S$ subarachnoid space, $T C$ tela choroidea, $V M$ velum medullare. a-f Same magnification. Scale bar $500 \mu \mathrm{m}$ 

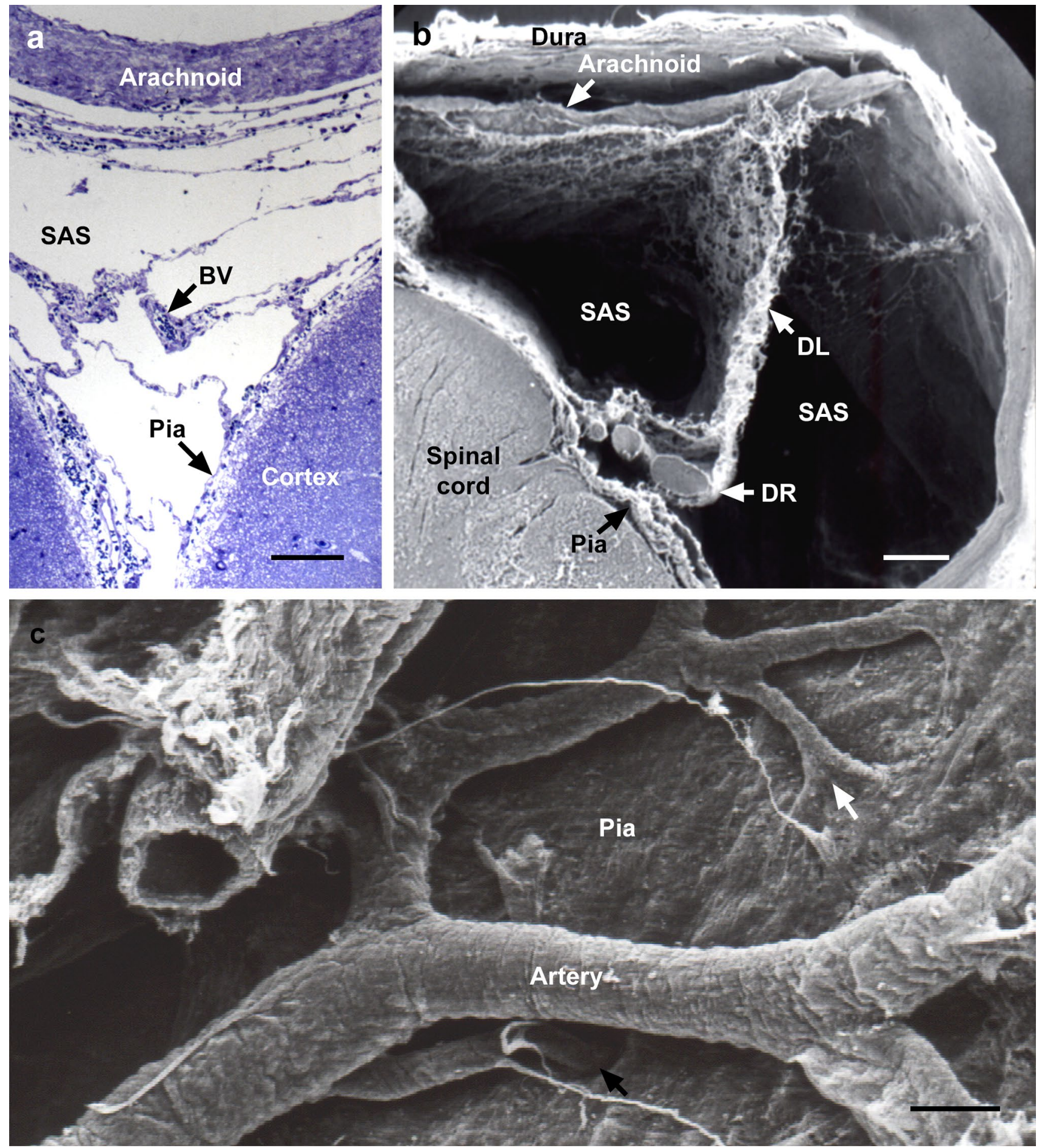

body of the arachnoid; desmosomes are also distributed to a lesser extent among leptomeningeal cells in the pia [4]. Most of the intercellular junctions between cells forming the pia, coating the trabeculae, arteries and veins in the SAS are relatively small gap junctions [13]. Immunocytochemistry of leptomeningeal cells in the adult human brain has identified the presence of desmosomes and tight junctions and of vimentin and epithelial membrane antigen (EMA) in the cytoplasm of leptomeningeal cells.

\section{Distribution of leptomeningeal cells in relation to the CNS}

Leptomeningeal cells form substantial sheets such as the human arachnoid and thin, delicate sheets that form the pia on the surface of the CNS and coat trabeculae in the SAS. 
4Fig. 3 Leptomeninges in the adult human brain and spinal cord. a Subarachnoid space over the human cerebral hemispheres. The arachnoid encompasses the subarachnoid space (SAS) and trabeculae, composed of collagen coated by leptomeningeal cells, extend across the SAS to join the pia covering the cerebral cortex. Blood vessels (BV) are suspended within the SAS by trabeculae. Resin section stained with toluidine blue. Scale bar $200 \mu \mathrm{m}$. Published with permission from Ref. [4]. b Subarachnoid space (SAS) and human spinal leptomeninges. Part of the spinal cord is seen bottom left and the thick layer of dura is at the top and to the right of the figure. The arachnoid has become focally detached from the overlying dura. A delicate, highly perforated dorsolateral ligament (DL) extends from the spinal cord to the arachnoid and incorporates dorsal spinal nerve roots (DR). The pia has a thick underlying layer of subpial collagen. Scale bar $600 \mu \mathrm{m}$. Published with permission from Ref. [68]. c Human cerebral subarachnoid space looking down on to the pia. Branches of a histologically proven artery enter the brain. In the upper part of the figure the pia is reflected on to the surface of an artery as it enters the underlying cortex (white arrow). By this arrangement, the subarachnoid space is separated by a layer of pia from the brain and from arterioles in the brain. Towards the bottom of the figure, a branch of the artery is associated with a V-shaped depression in the pia (black arrow) as the artery enters the cortex (see text). Scanning electron micrograph: Scale bar $150 \mu \mathrm{m}$ Published with permission from Ref. [45]

Thin sheets of leptomeningeal cells extend into the CNS parenchyma around penetrating arteries. Leptomeningeal cells also surround collagen bundles in the stroma of the choroid plexus [3] and in the cores of arachnoid granulations $[56,98]$. In this section, the structural features and functional roles of the human leptomeninges will be reviewed and related to leptomeninges in rodents.

\section{Arachnoid mater}

The arachnoid forms a translucent sheet that encompasses the outer aspects of the cerebral and spinal SAS. In humans, the arachnoid is some $200 \mu \mathrm{m}$ thick (Fig. 3a) and the main body of the arachnoid is composed of closely packed leptomeningeal cells joined by desmosomes and devoid of basement membranes [4]. In the outer barrier layer of the arachnoid that abuts on to the dura, the cells are joined by tight junctions that relate to the function of the normal arachnoid as a barrier to the passage of CSF out of the SAS and the entry of solutes and cells into the SAS [4, 65]. Sheet-like and filiform trabeculae with cores of collagen fibres coated by leptomeningeal cells extend across the human SAS to join the pia on the surface of the brain (Fig. 3a). Trabeculae divide the SAS into compartments and also suspend arteries and veins within the SAS [4, 45].

Human spinal leptomeninges form an outer barrier layer of arachnoid that is closely applied to the inner aspects of the dura [68]. Intermediate layers of arachnoid within the spinal SAS are composed of a complex array of perforated sheets, mainly over the dorsal aspects of the spinal cord [68,
103]; these perforated sheets may play a role in regulating the flow of CSF within the spinal SAS. Similar perforated sheets of leptomeninges form the delicate dorsolateral ligaments extending from the surface of the spinal cord to the arachnoid (Fig. 3b) [68, 103].

The SAS is shallower and much less extensive in rodents than in humans [23, 54]. Injection of tracers into the cisterna magna in rats shows that the SAS is most extensive over the base of the rodent brain and extends over the superiorlateral aspects of the cerebral hemispheres mainly as narrow channels adjacent to major branches of the middle cerebral arteries [54]. SAS surrounds the whole circumference of the rodent spinal cord.

\section{Pia mater}

In both rodents and humans, the pia is composed of a thin layer of leptomeningeal cells that are joined by gap junctions [13] and occasional desmosomes. For the most part, the pia is only one cell layer thick and is reflected on to arteries and veins as they enter or leave the surface of the CNS (Fig. 3c). By this anatomical arrangement, the subpial spaces and the surface of the CNS are separated from the SAS by a thin layer of pia mater $[4,45,68]$. Arteries enter the surface of the human brain in two ways as shown in Fig. 3c [45]. They may pass obliquely from the SAS to run parallel to the surface of the cortex as pial arteries in the subpial space (see white arrow in Fig. 3c). Alternatively, arteries enter perpendicular to the surface of the brain where they are associated with a V-shaped depression in the pia as shown by the black arrow in Fig. 3c. Pial arteries running parallel to the surface of the cerebral cortex are surrounded by a single layer of pia (Fig. 4a) and are separated from the glia limitans on the surface of the cortex by subpial space. Veins in the subpial space may or may not be surrounded by pia [4, 109]; the vein in Fig. 4b has no sheath of pia. Pial cells can be identified on the surface of vessels by the presence of intercellular gap junctions (Fig. 4a, c); desmosomes that are so prominent in the arachnoid are less frequently seen in the pia. Basement membranes associated with the cells of the pia may be incomplete (Fig. 4c, d). Within the subpial space delicate bundles of collagen fibres are interspersed with occasional inflammatory cells (Fig. 4a).

The pia and the subpial space are similar in structure in rodents and humans (Fig. 4a, b, d) but are more delicate in rodents; the basement membrane associated with the pia is variable in its extent. 

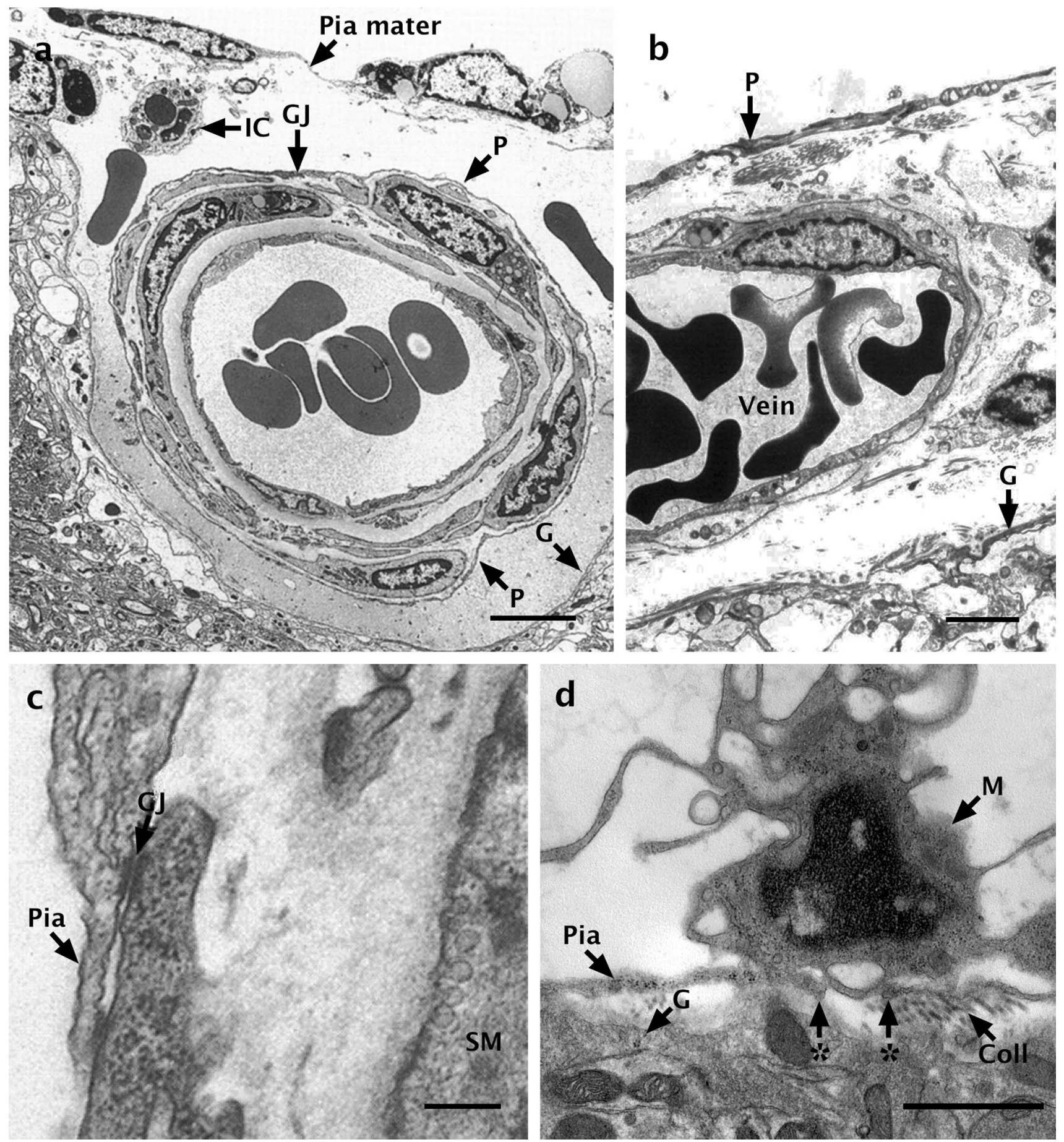

Fig. 4 Pia mater and subpial space in the adult human and mouse brain. a An artery in the human cortical subpial space. The pia is at the top and a thin layer of leptomeningeal cells derived from the pia (P) completely surrounds the arteriole in the subpial space. Gap junctions (GJ) (see c) join adjacent pial cells. Glia limitans $(\mathrm{G})$ is separated from the artery by subpial space. Inflammatory cell (IC). Scale bar $6 \mu \mathrm{m}$. Published with permission from Ref. [109]. b A vein in the human cortical subpial space. The pia $(\mathrm{P})$ is at the top of the picture and the thin-walled vein in the subpial space (SPS) has no coating of leptomeningeal cells. The glia limitans $(G)$ is at the bottom of

the picture and bundles of collagen fibres are seen within the subpial space (SPS). Scale bar $2 \mu \mathrm{m}$. Published with permission from Ref. [4]. $\mathbf{c}$ High magnification of a gap junction (GJ) between cells in the perivascular pia as indicated in a. Smooth muscle cell of the artery (SM). Scale bar $200 \mathrm{~nm}$. Published with permission from Ref. [109]. d Surface of cerebral cortex from a normal mouse showing pia, glia limitans $(\mathrm{G})$ and a shallow intervening subpial space containing collagen fibres (Coll). A macrophage (M) adheres to the surface of the pia and extends a process between two pial cells (between *arrows). Scale bar $1 \mu \mathrm{m}$ 
Perivascular compartments and perivascular spaces in the brain

\section{Arteries and veins in the cerebral cortex}

There are no perivascular (Virchow-Robin) spaces around arteries in the normal human cerebral cortex (Fig. 5a, b). As arteries enter the surface of the human and rodent brain parenchyma perpendicular to the surface of the cerebral cortex, they carry with them a single-layered sheath of pial cells that intervenes between the outer aspect of the artery and the glia limitans (Fig. 5a, b) [64, 103, 109]. Figure 5a shows an artery in the human cerebral cortex in which the perivascular compartment is composed of compacted layers of smooth muscle cells, basement membrane and pia closely associated with the basement membrane and astrocyte end feet of the glia limitans but there is no actual space [109]. A similar arrangement is seen in arteries in the mouse brain (Fig. 5b) [64]. Perivascular macrophages are embedded in the basement membranes that surround arteries and other blood vessels in the normal brain [37].

There has been much debate for many years regarding the presence of periarterial (Virchow-Robin) spaces around arteries in the cerebral cortex. Much of the confusion has arisen first from artefact in histological and electron microscope preparations due to swelling of perivascular astrocytes thus forming an artefactual space around cortical arteries [81]. Second, there has been misinterpretation of anatomical features. For instance, the subpial space shown in Fig. 4a has been mistaken for an intracortical periarterial space. Similarly, the subarachnoid space has been mistaken for perivascular spaces around cortical arteries. For example, in descriptions of the "glymphatic" system [46], electron micrographs were interpreted as intracortical periarterial spaces but are, in reality, subarachnoid space. In their illustrations [46], the authors show electron micrographs which they claim to show periarteriolar spaces within the brain. There are two layers of leptomeningeal cells with an intervening space in the figure; one layer of leptomeningeal cells is associated with the surface of an artery and the other layer is the pia mater associated with the glia limitans on the surface of the brain. This strongly suggests that the intervening space is subarachnoid space as intracortical arterioles have only one layer of leptomeningeal cells associated with their walls and no periarteriolar space (Fig. 5a) [109]. Furthermore, the entry of tracers from the CSF into the brain is along pial-glial basement membranes as shown by electron microscopy (Fig. 5b) [64] and by high-resolution confocal microscopy (Albargothy, Hawkes and Carare submitted paper) and not along periarteriolar "spaces".

Veins in the human cerebral cortex usually have only isolated leptomeningeal cells associated with their walls and no complete coating of leptomeningeal cells [109]; small blebs of perivenous space are seen [109]. Within the subpial spaces, the leptomeningeal layer may be absent around veins (Fig. 4b) [4] but as veins pass into the SAS they acquire a complete layer of leptomeningeal cells [109].

\section{Periarterial basement membranes as routes for bulk flow of fluid and solutes into and out of the brain}

Studies using high-resolution confocal microscopy and electron microscopy suggest that basement membranes in the walls of cerebral capillaries and arteries are major pathways for the bulk flow of fluid and solutes into and out of the brain $[18,64]$. Tracers injected into the cisterna magna enter the brain from the CSF along pial-glial basement membranes on the outer aspects of cerebral arteries [64] (Albargothy, Hawkes and Carare submitted paper) (Fig. 5a), and leave the brain along basement membranes within the walls of capillaries and arterioles (Albargothy, Hawkes and Carare submitted paper). Intracerebral injections of fluorescent tracers suggest that interstitial fluid and solutes drain rapidly out of the brain along basement membranes in the walls of capillaries and along basement membranes surrounding smooth muscle cells in the tunica media of cerebral arterioles and arteries [7, 16-18] [the Intramural Peri-Arterial Drainage (IPAD) pathway]; IPAD is impaired with age in mice [40]. Similarly, accumulation of amyloid $\beta$ (A $\beta$ ) in basement membranes of capillaries and arteries in human cerebral amyloid angiopathy (CAA) suggests that IPAD pathways are also impaired with age and Alzheimer's disease (for review see [18]). A $\beta$ initially accumulates in the lamina densa at the junction between adjacent smooth muscle cell basement membranes and at later stages completely separates the adjacent, fused basement membranes $[52,106]$. The molecular mechanisms involved in bulk flow of fluid and solutes along basement membranes in the walls of cerebral capillaries and arteries have yet to be fully characterised.

\section{Leptomeningeal cells surrounding arteries and veins in the cerebral white matter and basal ganglia}

As they pass from the cerebral cortex into the subcortical white matter, arteries tend to be surrounded by two layers of leptomeningeal cells (Fig. 5c), although one layer may be incomplete [26]. Veins, on the other hand, usually have only a single layer of leptomeninges [26]. In this way arteries in the white matter differ from those in the cortex and the arrangement of leptomeningeal coats may be related to the capacity of the perivascular spaces around white matter arteries to dilate [79, 104]. A similar arrangement of two coats of leptomeningeal cells is seen around arteries in the basal ganglia that may also exhibit dilatation of perivascular spaces (Fig. 5d) [75, 80]. 


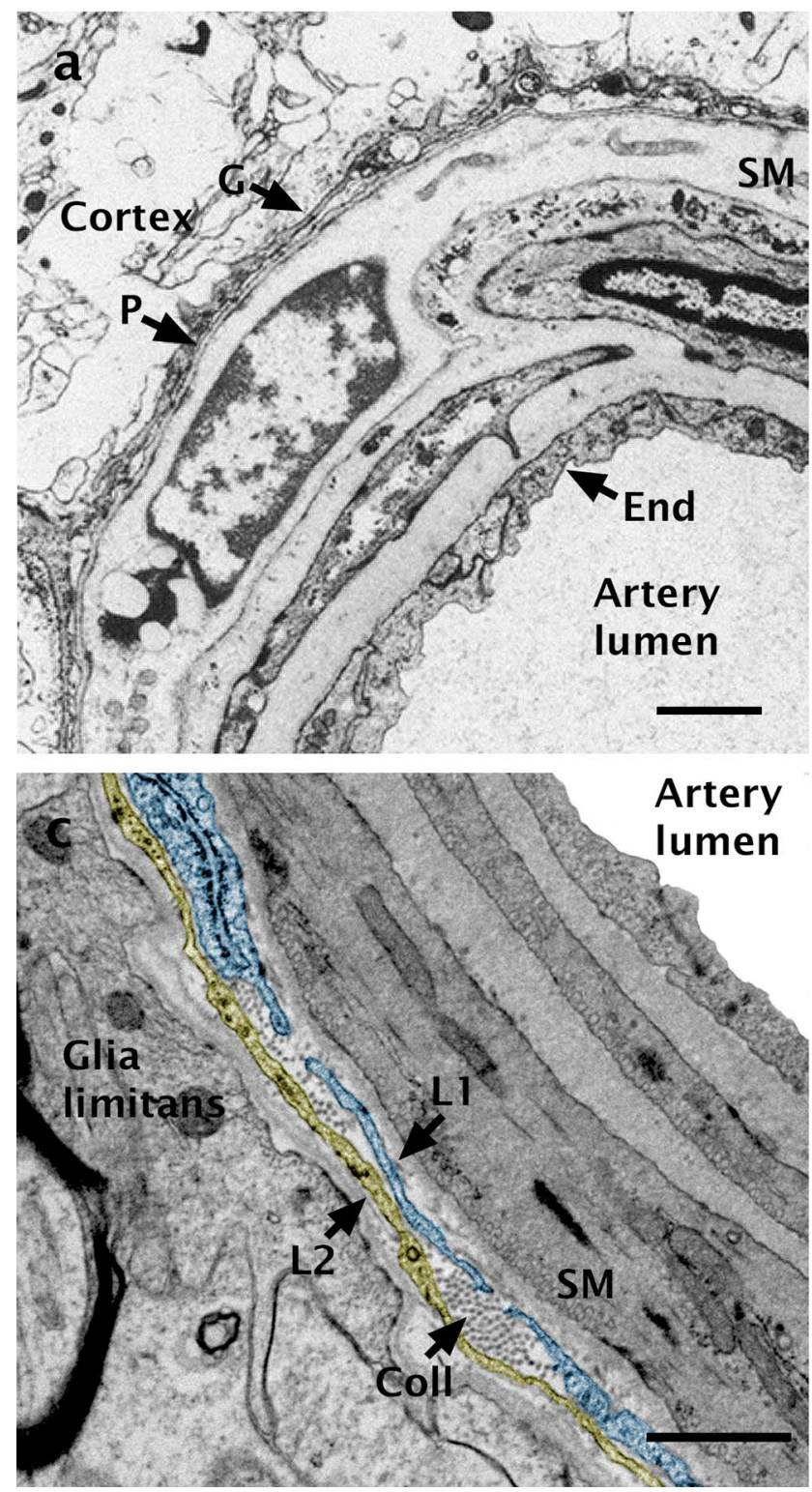

Fig. 5 Periarterial leptomeninges in the CNS. a An artery within the human cerebral cortex. There is no perivascular (Virchow-Robin) space around the artery as compacted layers of cells and basement membrane leave no space. A layer of pia (P) is closely apposed to the glia limitans $(\mathrm{G})$ on one side and the smooth muscle $(\mathrm{SM})$ coat of the tunica media of the artery on the other side. The lumen of the artery is surrounded by endothelium (End). Scale bar $1.3 \mu \mathrm{m}$. Published with permission from Ref. [109]. b Distribution in the brain of $15-\mathrm{nm}$ nanoparticles injected into the CSF. Groups of 15-nm nanoparticles $(\mathrm{Np})$ are seen in the pial-glial basement membrane of a cortical artery $5 \mathrm{~min}$ after injection into the CSF of the cisterna magna in a mouse. Layers of the artery wall can be identified moving outwards from the lumen lined by endothelium (End), smooth muscle cells (SM). A layer of pia is separated from the glia limitans (GL) of the brain parenchyma by a layer of pial-glial basement membrane (BM). The group of nanoparticles (np) in the pial-glial basement membrane indicates the pathway for the entry of CSF into the brain following the convective influx/"glymphatic" pathway. There is artefactual disruption of the pial-glial basement membrane associated with the nanoparticles as is frequently seen related to mineral deposits [3].
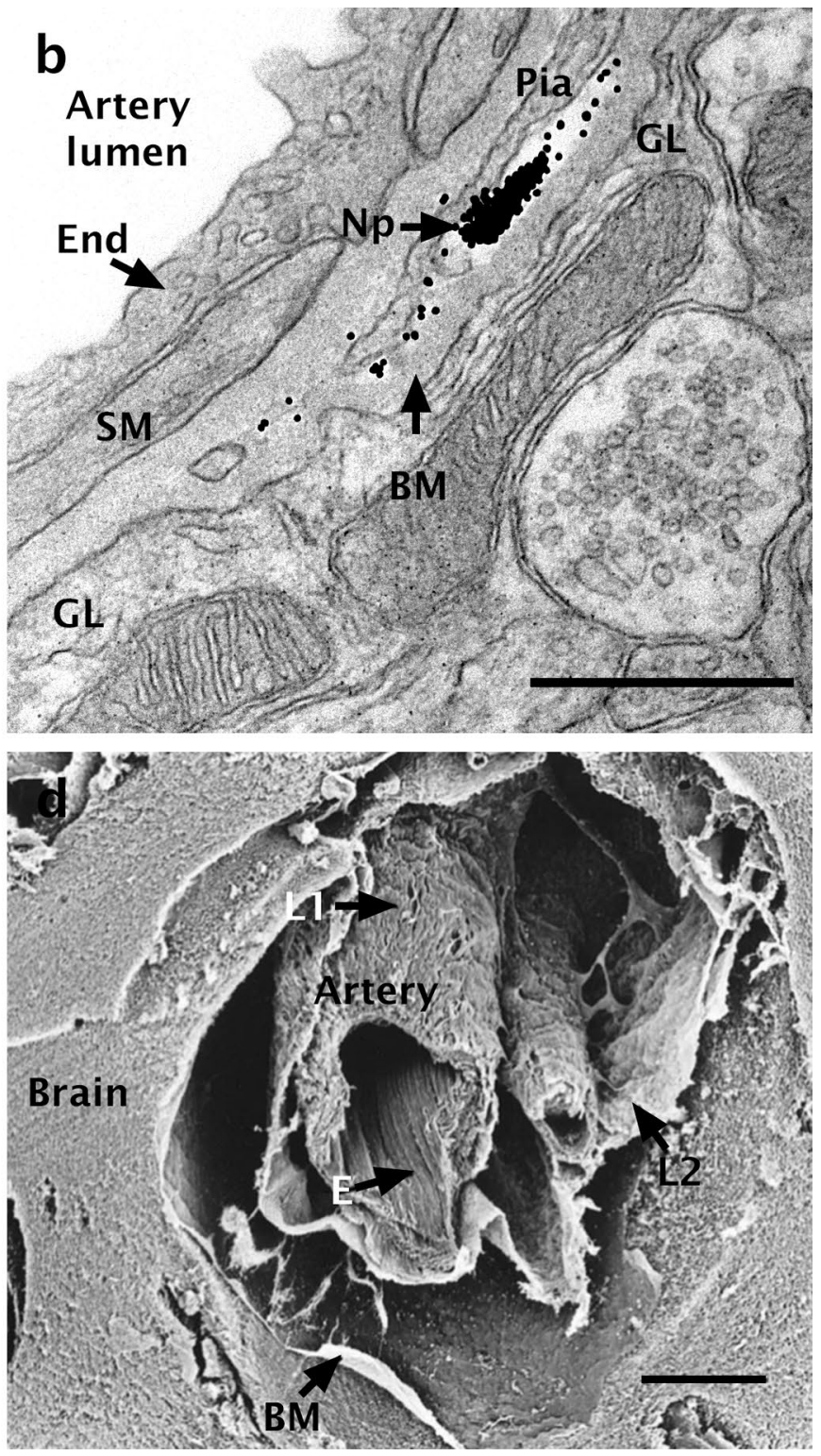

Scale bar $500 \mathrm{~nm}$. Published with permission from Ref. [64]. c An artery in the white matter of a 24-month-old dog brain. The lumen is surrounded by endothelium and smooth muscle cells (SM). There are two layers of leptomeninges (L1 (coloured blue) and L2 (yellow) surrounding the vessel wall and separating the smooth muscle coat of the artery from the glia limitans of the brain parenchyma. In this normal brain there is a narrow perivascular space between the layers of leptomeninges that may have the potential to expand as in human patients with cerebral amyloid angiopathy. Small bundles of collagen fibres (Coll) are present between the layers of leptomeninges. The methods are described in [26]; this unpublished image is from the same study. Scale bar $1 \mu \mathrm{m}$. d Dilated perivascular space in the basal ganglia of a 72-year-old human brain. A scanning electron micrograph shows an artery lined by endothelium (E). Transmission electron microscopy confirmed the presence of two layers of leptomeninges (L1 coating the artery wall and L2) either side of the dilated periarterial space. The outer layer of leptomeninges is partly separated from the basement membrane (BM) of the glia limitans. Scale bar $330 \mu \mathrm{m}$ Published with permission from Ref. [75] 
Dilatation of perivascular spaces in cerebral white matter and basal ganglia

Although there are no perivascular spaces around arteries in the cerebral cortex, spaces may be present around arteries in the cerebral white matter [19, 79, 104], basal ganglia [75] and midbrain and they may become very large [80]. The capacity for periarterial spaces to dilate in the white matter and basal ganglia appears to correlate with the arrangement of the leptomeninges around those vessels. There is one layer of leptomeningeal cells around arteries in the cerebral cortex but there tends to be two layers of leptomeninges surrounding arteries in the white matter and basal ganglia $[26,75,109]$.

Dilated perivascular spaces around arteries in the human cerebral white matter can be detected by MRI and by histology and have been associated with CAA and consequent failure of drainage of interstitial fluid [19, 79, 104]. It appears that CAA impedes the drainage of interstitial fluid from cerebral white matter and results in dilatation of periarterial spaces, but only in the white matter and not in the grey matter of the cerebral cortex $[19,79,104]$.

Dilatation of perivascular spaces in the basal ganglia is related to age and small vessel disease and can be detected by MRI [38] and by histology [75]. Two layers of leptomeninges surround arteries in the basal ganglia and dilated perivascular spaces are encompassed on each side by a single layer of leptomeninges as seen by scanning electron microscopy (Fig. 5d) and confirmed by transmission electron microscopy [75].

\section{Leptomeninges as barriers and facilitators in the CNS}

The most prominent barrier function performed by the leptomeninges is the arachnoid that surrounds the outer aspect of the CNS; it is impermeable to CSF and thus contains the CSF within the SAS and separates the CSF from blood vessels in the dura that have no blood-brain barrier or blood CSF barrier. Leptomeningeal cells also perform other barrier functions particularly as intervening cell layers between collagen fibres and the CSF. Inflammatory cells appear to readily penetrate the thin layers of leptomeningeal cells such as the pia but not the thicker arachnoid barrier layer. Although veins in the SAS are coated by a layer of leptomeningeal cells, the main barrier to entry of inflammatory cells from the blood into the CSF in the SAS is the vascular endothelium lining veins in the SAS and subpial spaces [30, 31]. The arachnoid barrier, besides containing the CSF within the SAS, also plays an important role in preventing activated immune cells invading the CSF from dural blood vessels.
Leptomeningeal cells also facilitate the circulation of CSF and the attachment of inflammatory cells, tumour cells and the bacteria within the SAS. There is a complete lining of leptomeningeal cells around the SAS; furthermore leptomeningeal cells cover collagen bundles in the stroma of the choroid plexus, line the pathways for drainage of CSF into the blood through arachnoid granulations and line the pathways for lymphatic drainage of CSF into nasal lymphatics. In addition, extensions of leptomeningeal cells into the CNS along the outer walls of arteries facilitate entry of CSF into the CNS.

\section{Barriers}

\section{Arachnoid mater}

In humans, the main body of the arachnoid is composed of closely packed leptomeningeal cells joined by desmosomes [4]. However, the outer barrier layer of the arachnoid that abuts on to the dura is composed of cells joined by tight junctions that prevent the escape of CSF from the SAS [4]. Arachnoid also acts as a barrier to the spread of inflammatory cells from the SAS in cases of leptomeningitis and resists the spread of pus from subdural infections into the SAS.

\section{Leptomeningeal cells separate collagen fibres from the CSF in the subarachnoid space}

The SAS is surrounded by connective tissue but leptomeningeal cells separate collagen fibres from the CSF. In this way, leptomeningeal cells form a smooth surface that separates cells circulating in the CSF from underlying tissue elements; this is similar to the way in which vascular endothelial cells form a surface for the smooth transport of blood. As discussed below, leptomeningeal cells also form a surface for the attachment of inflammatory cells, tumour cells and bacteria within the subarachnoid space. The inner layer of the arachnoid facing the CSF has a thin underlying layer of collagen that extends into trabeculae that cross the SAS to join the pia or suspend subarachnoid blood vessels within the SAS [4, 45]. A layer of leptomeningeal cells separates the collagen in the arachnoid, the subarachnoid trabeculae and in the subpial compartment from the CSF (Fig. 6a). The layers of leptomeningeal cells performing this barrier function are often only one cell thick and joined by gap junctions or desmosomes $[4,13]$.

The principle of leptomeningeal cells separating collagen from fluid applies not only in the SAS but is also seen in the stroma of the choroid plexus and in cores of arachnoid granulations. 


\section{Choroid plexus}

Bundles of collagen are present in the stroma of the choroid plexus but they are surrounded by leptomeningeal cells (Fig. 6b) [3]. In older humans, spheres of collagen fibres, produced and surrounded by leptomeningeal cells, may become calcified to form calcospherites in the stroma of the choroid plexus [3]. The anatomical arrangement suggests that fluid, solutes and inflammatory cells passing out of the blood vessels into the stroma and trafficking towards the choroid plexus epithelium, the site of the blood-CSF barrier, are separated from collagen bundles by leptomeningeal cells in a similar way to the separation of collagen from CSF in the SAS.

\section{Arachnoid granulations}

The SAS is continuous with the core of each arachnoid granulation such that CSF flows into a network of channels in the core of the granulation (Fig. 6c) [56, 98]. Delicate trabeculae of collagen fibres form the walls of the channels but the trabeculae are coated by leptomeningeal cells that separate the collagen from the CSF within the channels. Each granulation has a cap of compacted leptomeningeal cells through which channels pass to carry CSF to the venous endothelium $[55,56,98]$. CSF then appears to pass by macrovacuolar bulk flow through the venous endothelium into the blood [97]. By this arrangement, CSF is separated from collagenous elements in the arachnoid granulations by a coating of leptomeningeal cells.

\section{Facilitators}

Layers of leptomeningeal cells lining the SAS, the stroma of the choroid plexus, drainage channels in arachnoid granulations and the channels that drain CSF into nasal lymphatics [54] facilitate the production, circulation and drainage of CSF. They also facilitate the movement of inflammatory cells within the SAS. The leptomeningeal cells of the pia offer little resistance to the passage of inflammatory cells [45, 57] (Fig. 4d) although they do block the passage of erythrocytes and particulate matter [45]. Similarly, the leptomeningeal cells coating veins in the SAS appear to offer little resistance to the passage of $\mathrm{T}$ lymphocytes, polymorphonuclear leukocytes and monocytes entering the SAS from the blood $[85,102]$. The major barrier to the passage of inflammatory cells from CSF into the CNS appears to be the glia limitans [31].

Most of the research into traffic of inflammatory cells into the CSF and CNS has been on experimental autoimmune encephalomyelitis (EAE) as an animal model of multiple sclerosis. Experiments in EAE suggest three potential routes for the entry of encephalitogenic T cells into the CNS, either directly from the blood or via the CSF. Migration of T cells from the blood into the CNS parenchyma in inflammation is by a two-step process $[30,31]$. Step 1 : T cells in the blood with activated $\alpha 4 \beta 1$-integrins (VLA4) on their surfaces engage VCAM-1 on endothelial cells and migrate into the perivascular spaces around postcapillary venules. Step 2: from the perivenular spaces, $T$ cells penetrate the basement membrane and astrocyte processes of the glia limitans to enter the CNS parenchyma; this step is facilitated by the expression of matrix metalloproteinases (MMPs) produced by macrophages [30]. Encephalitogenic T cells also migrate across the walls of leptomeningeal veins directly into the CSF in the SAS [85]. Another route of entry of T cells into the CSF appears to be through the choroid plexus and blood CSF barrier into the ventricles [78].

$\mathrm{T}$ lymphocytes in the spinal SAS in EAE attach to the leptomeninges through steps reminiscent of vascular adhesion in the CNS blood vessels involving integrins VLA-4 and LFA-1 on lymphocyte cell surfaces binding to their respective ligands; the integrins appear to be activated by chemokines produced by resident macrophages [85]. Chemokine signalling via CCR5/CXCR3 and antigenic stimulation of $\mathrm{T}$ cells in contact with leptomeningeal macrophages enforces their adhesiveness to the leptomeninges. $\mathrm{T}$ cells that become detached from leptomeninges and float free in the CSF display significantly lower activation levels compared to $\mathrm{T}$ cells attached to the leptomeninges and from the parenchyma of the CNS [85]. This suggests that attachment to the leptomeninges induces more activation in the $\mathrm{T}$ cells. Invasion of $\mathrm{T}$ cells into CNS tissue from the CSF would entail crossing the glia limitans which is the main barrier on the surface of the CNS to the passage of inflammatory cells into the CNS parenchyma [30].

\section{Arteries and leptomeningeal cells as facilitators for the entry of CSF into the CNS}

Layers of leptomeningeal cells that accompany arteries as they enter the surface of the CNS appear to facilitate the entry of CSF into CNS tissue. When tracers are injected into the CSF, they enter the brain along the pial-glial basement membranes on the outer aspects of cerebral arteries (Figs. 5b, 6a) [64]. This suggests that leptomeninges play a facilitating role in fluid balance between CSF and interstitial fluid within the CNS. Convective flow of CSF and interstitial fluid through the brain parenchyma driven by aquaporin 4 as suggested by the "glymphatic" hypothesis [46] has been strongly contested $[2,91]$. Furthermore, the suggestion that tracers entering the brain from the CSF are eliminated along perivenous pathways in the "glymphatic" system [46] has also been strongly disputed by Albargothy, Hawkes and Carare (submitted paper) who have shown that such tracers 
a
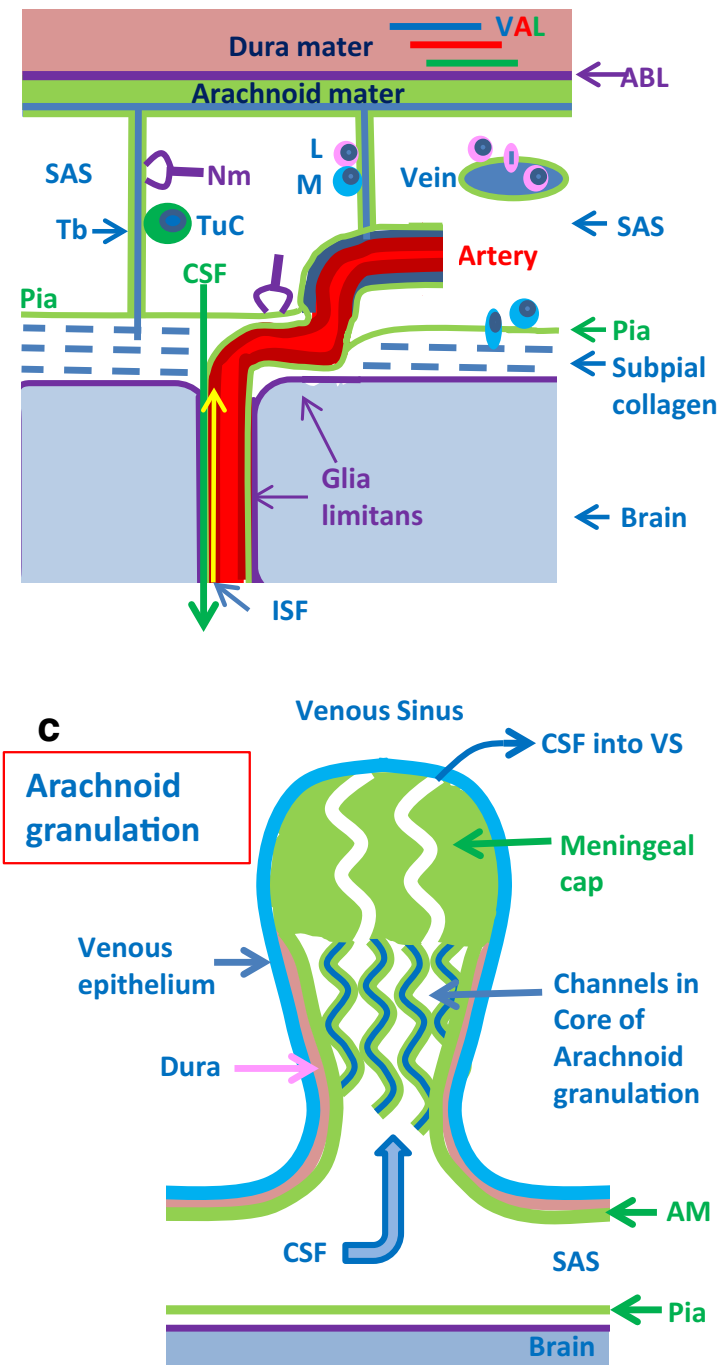

Fig. 6 Leptomeninges as barriers and facilitators for the movement of fluid and cells. a The subarachnoid space (SAS), leptomeninges and the surface of the brain. Veins, arteries and lymphatics (VAL) in the dura are separated from the arachnoid by the arachnoid barrier layer $(\mathrm{ABL})$ that appears to prevent the escape of CSF from the SAS and the entry of solutes from the "leaky" dural blood vessels into the CSF. Collagen fibres (blue layers) are separated from CSF in the SAS by layers of arachnoid and pial cells (green). Collagen bundles in the cores of trabeculae ( $\mathrm{Tb}$ ) that cross the subarachnoid space are also separated from CSF by leptomeningeal cells (green). Lymphocytes (L) and monocyte/macrophages (M) enter the SAS from the blood via the walls of veins and adhere to leptomeningeal cells and cross the pia. Similarly, tumour cells (TuC) and bacteria (Neisseria meningitidis $(\mathrm{Nm})$, derived from the blood, adhere to leptomeningeal cells lining the SAS. Periarterial compartments facilitate entry of CSF into the brain along pial-glial basement membranes on the outside of the artery (green arrow). Interstitial fluid (ISF) from the brain drains along basement membranes in the walls of capillaries and in the tunica media of cerebral arteries that form the Intramural PeriArterial Drainage (IPAD) pathway as indicated by the yellow arrow.
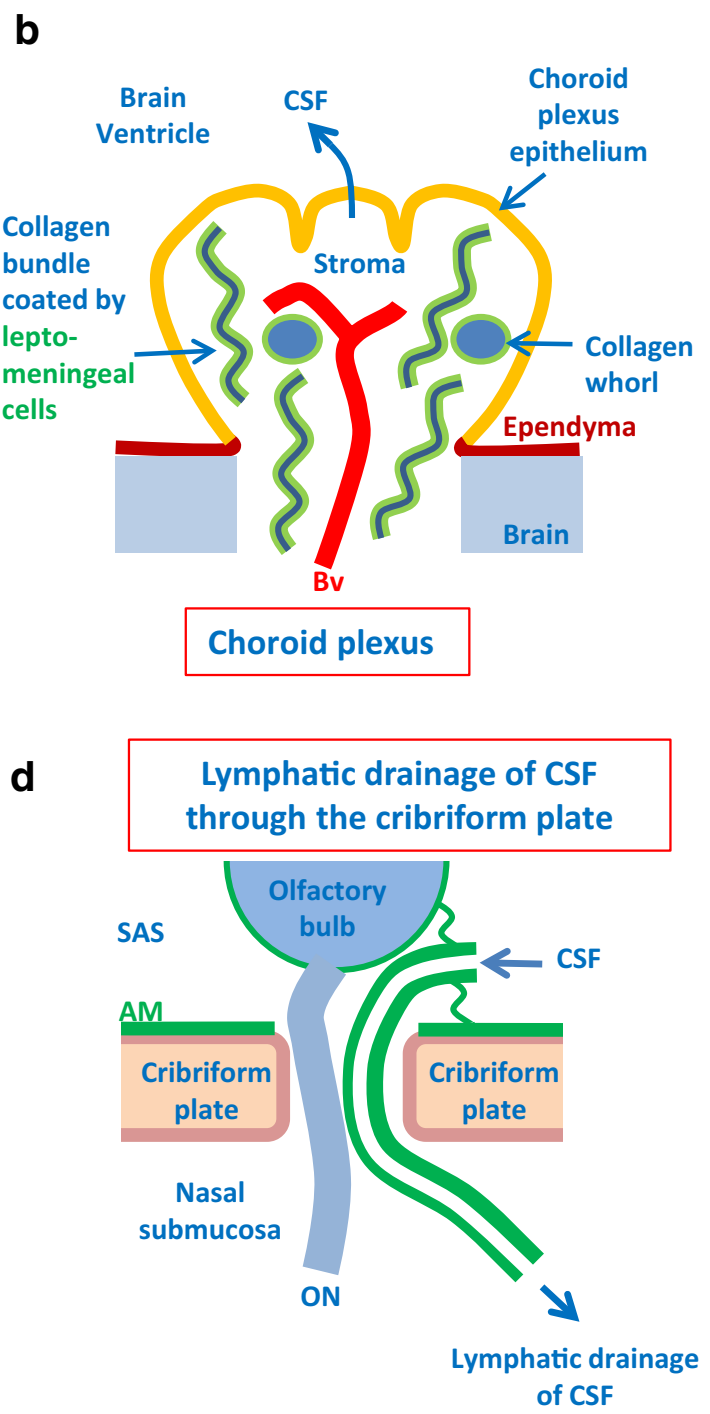

The glia limitans (purple) forms a barrier to the entry of inflammatory cells into brain tissue. b Choroid plexus. Leptomeningeal cells (green) cover collagen bundles and collagen whorls within the stroma of the choroid plexus. Fluid and solutes entering the CSF from the choroid plexus are derived from blood vessels $(\mathrm{Bv})$ in the stroma but the blood CSF barrier is located in the choroid plexus epithelium. c Arachnoid granulation. CSF passes from the subarachnoid space (SAS) into channels in the core of the granulation. The channels are formed by trabeculae that have a core of collagen (blue) covered by leptomeningeal cells (green). CSF then flows into channels within the meningeal cap to reach the venous endothelium and pass into the venous sinus (VS). In this way, the CSF is separated from collagen bundles by leptomeningeal cells as it drains through the arachnoid granulation. Arachnoid: AM. d Lymphatic drainage of CSF through the cribriform plate. Channels lined by leptomeningeal cells (green) pass from the subarachnoid space (SAS) inferior to the olfactory bulbs, through the cribriform plate alongside olfactory nerves $(\mathrm{ON})$ into the nasal mucosa. These channels develop during foetal life and form a major pathway for drainage of CSF to lymph nodes. Arachnoid: AM 
are eliminated from the brain along basement membranes in the walls of capillaries and arteries-IPAD (Fig. 6a).

Leptomeningeal cells facilitate lymphatic drainage of CSF via the cribriform plate and nasal submucosa [54] in both foetal and adult human and rodent brains (Figs. 1c, 6d). Channels lined by leptomeningeal cells form in the subarachnoid space under the olfactory bulbs and pass through the cribriform plate alongside olfactory nerves into the nasal submucosa [54]. This system for the drainage of CSF appears to develop before the appearance of arachnoid villi and granulations.

\section{Tumour cell invasion of subarachnoid spaces and adherence to leptomeninges}

Three major categories of tumours cause Meningeosis neoplastica: namely carcinomas, lymphomas and primary tumours of the CNS, particularly medulloblastomas [28, 77]. However, little is known about the mechanisms by which tumour cells enter the SAS or are maintained within the CSF.

Tumour cells frequently accumulate in regions in which there is reduced circulation of CSF, such as the basal cisterns, cauda equina and hippocampal fissures. Medulloblastomas have received considerable attention as most deaths from this disease are due to leptomeningeal metastases [77]. Four major molecular subgroups of medulloblastoma have been recognised: wingless (WNT), sonic hedgehog (SHH), group 3 and group 4 [77] but whole genome landscapes have revealed additional new molecular subtypes [69]. It is predicted that molecular characterisation will lead to more targeted therapies for leptomeningeal metastases of medulloblastoma [67]. In vitro and in vivo data suggest that expression of $\alpha 9$ and $\beta 1$ integrins, in combination with tenascin in the extracellular matrix, mediate the adhesion of medulloblastoma cells to the leptomeninges [33]. Blockade of $\alpha 9$ and $\beta 1$ integrin binding by antibodies reduces tumour cell survival which suggests that adhesion of medulloblastoma cells to the meninges is necessary for the survival and proliferation of tumour metastases in the SAS [33].

\section{Leptomeninges as barriers and facilitators of bacterial meningitis}

Leptomeningitis is an acute, compartmentalised intracranial inflammatory response centred on the leptomeninges and can be caused by a plethora of different bacteria that can gain access to the SAS [20]. Neisseria meningitidis (meningococcus) is a well-studied exemplar for understanding the interactions between bacterial ligands and receptor molecules on blood vessel endothelium and the leptomeninges. In the pathogenesis of meningococcal meningitis, the bacteria interact with several physical cellular barriers including the mucosal epithelium of the nasopharynx, the blood compartment, endothelial cells of blood vessels that separate the blood from the CSF-filled SAS, and the leptomeninges. Meningococci express a variety of surface ligands that mediate their attachment to human cells and enable meningococci to cross these cell barriers, by interand/or intracellular routes.

\section{Meningococcal bacteraemia}

Bacteraemia is a pre-requisite for the entry of bacteria into the CSF and the development of meningitis. The fact that meningitis commonly presents without fulminant sepsis also suggests that bacteraemia is asymptomatic. Meningococci have evolved strategies to avoid innate immune defence mechanisms and they express several factors that are important for survival in the blood. Both the capsule polysaccharide (CPS) and lipooligosaccharide (LOS) exhibit characteristic antigenic variation and molecular mimicry that enable meningococci to avoid antibody deposition, complement-mediated killing and phagocytosis. For example, the $\alpha(2-8) \mathrm{N}$-acetyl-neuraminic acid linked homopolymer of serogroup B CPS is structurally identical to a modification of mammalian neural cell adhesion molecule (N-CAM) [95]. Sialylation of LOS enables meningococci to mimic host cell surfaces that express sialic acid [60] and to interact with myeloid cell SIGLECs (sialic acid-binding, immunoglobulin-like lectins). Phosphoethanolamine modification of LOS can increase adherence to human cells and also protects meningococci from neutrophil extracellular trap (NET)-bound cathepsin G [58]. Natural release of outer membranes (OM) and expression of the ZnuD surface protein also enable meningococci to escape NET interactions. Other surface-exposed proteins important for bacterial survival include TspB (T/B cell-stimulating protein B), TbpA/ $\mathrm{TbpB}$ (Transferrin-binding proteins), LbpA/LbpB (Lactoferrin-binding proteins), $\mathrm{HpuA} / \mathrm{HpuB} / \mathrm{HmbR}$ (Haemoglobinbinding receptors), Ig-binding protease and NHBA (Neisseria Heparin Binding Protein). Meningococci also avoid complement killing through expression of Porin A that binds the complement inhibitor $\mathrm{C} 4 \mathrm{bp}$ protein [47], and of fHbp (factor $\mathrm{H}$ binding protein), NspA (Neisserial surface protein A) and PorinB3, which all bind human factor $\mathrm{H}[35,88]$.

\section{Attachment and penetration of vascular endothelium}

Meningococci show a tropism for microvasculature endothelial cells and bacterial invasion of the SAS requires meningococci to breach the blood-CSF barrier (BCSFB), located either at the choroid plexus or in the veins within the SAS. Post-mortem studies of meningococcal meningitis patients demonstrated the adherence of bacteria to endothelial cells of choroid plexus capillaries, but no bacteria were found 
inside choroidal epithelial cells or penetrating the tight junctions [76]. Furthermore, leptomeningitis is centred within the SAS and ventriculitis is usually a late complication, indicating that unchecked bacterial proliferation in the SAS eventually spreads to other CSF-filled compartments. Thus, meningococci probably do not traverse the BCSFB at the choroid plexus and are likely to enter the CSF via veins in the SAS, with the blood vessel endothelium as the first barrier.

Meningococcal adherence to the endothelial cell barrier and the mechanism of traversal has been extensively studied [24]. The Type 4 pilus (Tfp) adhesin promotes the initial binding event between meningococci and endothelial cells, but only in microvessels where blood flow shear stresses are low. Expression of the Tfp-associated protein PilX stimulates bacterial aggregation and spreading across the cell surface [41]. Adherence occurs through the interaction between Tfp and the CD147 (extracellular matrix (ECM) MMP inducer, EMMPRIN or Basigin)- $\beta 2$-adrenergic receptor ( $\beta 2 \mathrm{AR})$ complex, with the Tfp subunit PilE protein and associated PilV protein interacting directly with the extracellular $\mathrm{N}$-terminal domain of the $\beta 2$-adrenergic receptor. Activation initiates a signalling pathway that leads to the formation of 'cortical plaques' of cytoplasmic ezrin and ezrin-binding and actin microfilament-binding proteins. Signalling leads to relocation of vascular endothelial cadherin from endothelial cell junctions at the sites of bacterial adherence, and also induces the production of MMP8 that promotes cleavage of the tight junction protein occludin [87]. Other Tfp-associated proteins that may be involved in cell interactions include the tip-associated PilC1/C2 and a phosphorylcholine modification of Tfp that interacts with Platelet Activating Factor receptor [48]. Adherence of meningococcal also stimulates endothelial cells to release cytokines, chemokines and reactive oxygen and nitrogen species [21], that contribute to cell stress and degradation of intercellular junctions. Thus, crossing the endothelial barrier is primarily by the intercellular route. An intracellular route of invasion is possible, though considered to be secondary: retraction of Tfp draws meningococci towards the endothelial cell plasmalemma and concomitant down-regulation of CPS expression exposes $\mathrm{OM}$ adhesins and invasins that can interact with endothelial cell receptors to promote internalisation of bacteria. These include the well-characterised Opa (colony opacity-associated), Opc (5C), NadA (Neisserial adhesin A) proteins and the OmpA-like sequence of RmpM (Reduction modifiable protein $\mathrm{M}$ ) (Table 2).

\section{Penetration of leptomeningeal layers}

After crossing the vessel endothelium, meningococci will encounter a thin layer of connective tissue and then the leptomeningeal coating that encloses the vein within the
CSF-filled SAS. The mechanism by which meningococci penetrate this leptomeningeal coating is unclear, but the fact that meningeal cells do not internalise meningococci suggests intercellular penetration, perhaps as a consequence of degradation of desmosomes and other junctions by endothelial cell metabolites. It is possible that the ErbB family receptor protein EGFR on leptomeningeal cells (Table 2) is activated by meningococcal infection. In endothelial cells, EGFR, Erb2 and Erb4 are activated in response to meningococcal infection and involved in the internalisation of bacteria [90]. However, activation of EGFR on the leptomeninges could be involved in weakening intercellular junctions to allow transmigration of meningococci, mimicking a process that has been described for transmigration of $N$. gonorrhoeae across polarised epithelial cells [29].

The ability of meningococci to weaken endothelial and leptomeningeal intercellular junctions is a trafficking mechanism shared with T lymphocytes, B cells, PMNL and other myeloid cells for their entry into the CNS, and includes activation of MMP proteins [30]. However, the nature of the ligands used by trafficking immune cells and their targeted receptors appear to be distinct from those used by meningococci. Interestingly, Tfp-mediated adherence of Neisseriae to the uropod of polarised PMNL suggests a hypothesis that the bacteria can hitchhike on PMNL both to hide from their phagocytic activity and to enable dissemination through cell barriers [92].

\section{Adherence of meningococci to leptomeningeal cells}

The CPS and Tfp phenotype of $N$. meningitidis, which is normally isolated from blood and the CSF, shows a specific predilection for binding to leptomeninges but not to cortical brain tissue (Fig. 7a, b) [39]. Meningococci adhere similarly to the surface of cultured tumour cells derived from benign meningiomas arising from the leptomeninges (Fig. 7c). Meningioma cells share many structural features with normal leptomeningeal cells [32]; they are characterised by the presence of desmosomes, and, except in certain sites in the leptomeninges, tight junctions are absent. Both types of cell express the cytoplasmic intermediate filament proteins nestin Type VI, cytokeratin and vimentin Type II and the microtubule-associated protein doublecortin and both secrete Type IV collagen, Type III procollagen, tenascin and fibronectin ECM proteins. Meningioma cells provide an in vitro model for studying meningitis and all the major meningeal pathogens can adhere to these cells (Fig. 7c) [5, $9,34,39$ ], although the nature of the bacterial ligands and meningeal cell receptors has not been explored extensively.

The type 4 pilus (Tfp) is the primary ligand that mediates adherence of meningococci to leptomeningeal cells [39], and Tfp-mediated adherence is not influenced by CPS expression, the antigenic class of pilus expressed (Class I or Class 
Table 2 Profile of known and potential surface receptor molecules on human leptomeningeal cells and meningioma cells

Molecule
Laminin receptor 1 (LamR; also known as RPSA)-galectin 3 (GAL3)
complex)
Heparan sulphate proteoglycans (HSPG)
Integrins ( $\alpha 1, \alpha 2, \alpha 3, \alpha 4, \alpha 5, \alpha 6, \beta 1, \beta 4)$
MARCO (Class A Mo scavenger receptor (SR-A) and macrophage
receptor with a collagenous structure)
receptor with a collagenous structure)

CD46 (membrane co-factor protein)

TLR2

\section{TLR4}

Epidermal growth factor receptor (EGFR)

\section{HLA-DR}

Interleukin-1R

\section{N-CAM}

Fc $\gamma$ receptors

Bone morphogenetic protein (BMP) 4 and 7 receptors

\section{CD44}

Desmosomal desmoplakin

G protein-coupled melatonin receptor Mel1a

YKL-40

$\beta$-Type platelet-derived growth factor (PDGF) receptor

CXCR4 and CXCR7 chemokine receptors

Endothelin receptors

Epithelial membrane antigen

Fibroblast growth factor receptor-1 (FGFR-1)

Mesothelin

Prolactin receptor (PRLR)

Sex hormone receptors (progesterone, oestrogen, androgen, aromatase) Somatostatin receptor (hsst) $2 \mathrm{a}$

TGF- $\beta$ receptors

Histones
Receptor function and meningococcal ligand recognised

Binds PorA and PilQ [73] and NhhA (Neisseria hia/hsf homologue; Msf, meningococcal surface fibril) [84]

Binds NhhA [84], NHBA (Neisseria Heparin Binding Antigen) [99], Opa and Opc proteins [42]

Expressed to varying degrees in meningioma/meningeal cells. Bind Opa proteins (which also recognise CEACAM (carcinoembryonic antigenrelated cell adhesion molecule) family receptor proteins) and Opc protein [42]. $\beta 1$-integrin binds NadA (Neisserial adhesin A (autotransporter TAA adhesin-invasin) [66]

Expressed on (rodent) meningeal cells. Binds to various meningococcal proteins (NMB0278, DsbA; NMB0346, NMB0667, NMB1513, hypothetical; NMB1220, Stomatin/Mec-2 family protein; NMB1567, Macrophage infectivity potentiator) [74]

Expressed on all cell types except erythrocytes. Putative receptor for Tfp [51]

Toll-like receptor 2: pathogen recognition receptor (PRR) for Grampositive lipoteichoic acid and other lipoproteins and meningococcal PorB [96]

Toll-like receptor 4: PRR for LOS endotoxin

Transmembrane protein with intrinsic tyrosine kinase. Microbial ligandbinding to EGFR potentially activates cell signalling, phosphorylates protein kinases, and rearranges cytoskeletal proteins, thus facilitating pathogen uptake

Do phagocytic arachnoid cells act as antigen-presenting cells?

Binds Interleukin 1 cytokine

Surface glycoprotein CD56; mimicked by serogroup B CPS

Potential phagocytosis-related functions; increased by GM-CSF production

Expressed on leptomeninges-BMPs influence vascular development in this tissue

Multi-structural glycoprotein with functions in cell proliferation, differentiation, migration, angiogenesis, signalling pathways for cell survival, presentation of innate molecules and proteases to receptors

Protein component of desmosomes, which are meningeal cell intercellular junctions. Desmosomes function in cell-cell adhesion and for the attachment of intermediate filaments (IF)

Receptor for melatonin that may play role in early neural development

Heparin- and chitin-binding glycoprotein, participates in inflammatory states

PDGF stimulates tumourigenesis in arachnoid cells

Involved in tumour cell proliferation and survival

Role in tumour growth

Marker of meningioma; also known as mucin glycoprotein CD227,

MUC1, episialin. Normally acts as a barrier to apical cell surfaces

Associated with meningioma cell growth and tumourigenesis

Function unknown, possibly a tumour marker

Detected in meningiomas; proliferative effects

May play a role in the tumorigenesis of meningiomas

Binds somatostatin hormone; diagnostic marker for meningioma

Receptor loss related to malignancy

Intracellular proteins that can associate with App (Adhesion and penetration autotransporter protein) and MspA/Aus1 (meningococcal serine protease A/autotransporter serine protease 1) [53] 

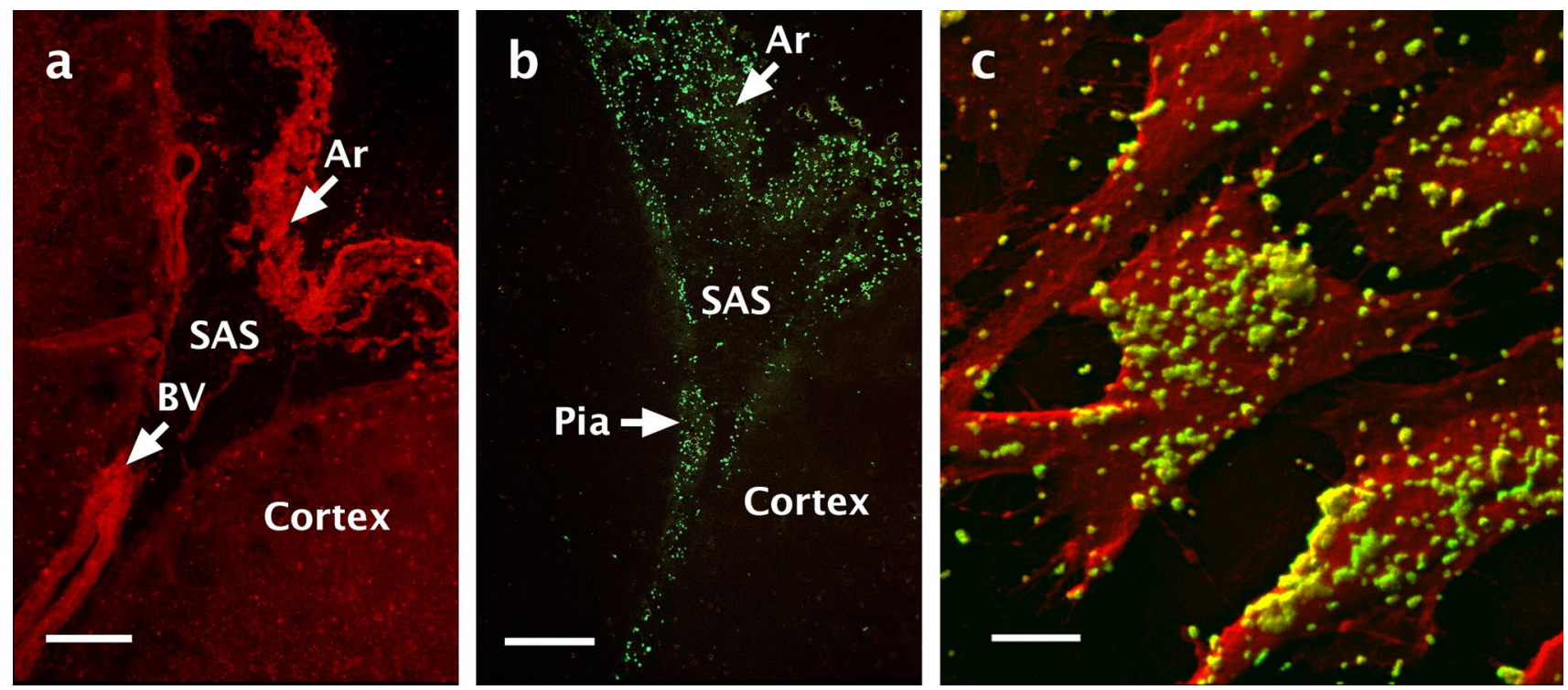

Fig. 7 Interactions of pathogenic Neisseria meningitidis with human leptomeninges. a Control cryostat section of human brain stained by immunocytochemistry for vimentin. Arachnoid (Ar) with underlying sulcus and subarachnoid space (SAS) containing CSF that separates cerebral cortex on either side. Blood vessel (BV) in the sulcus. b The same section as in a infected with $N$. meningitidis (green) that adhere to the leptomeningeal cells in the arachnoid, coating trabeculae and in the pia and coating blood vessel wall within the subarachnoid space

II) or by variable expression of PilC1 protein. However, variation within Class I pilin that modifies pilin structure and/or the ability to form bundled pili, does influence meningococcal adherence to leptomeningeal cells, as similarly observed with epithelial and endothelial cells. For capsulated bacteria, expression of Opc protein is not involved in mediating adherence, whereas expression of Opa protein does increase the association of capsulated meningococci that express low-adhesive pili, but do not influence the association of high-adhesive piliated bacteria [39]. Expression of TspA (T cell-stimulating protein A) has been reported to contribute to the adhesion of meningococci to meningioma cells [72]. Only one other protein, the Adhesin Complex Protein, has been reported to bind directly to cell surfaces and mediate adherence of capsulated meningococci to meningeal cells [44]. A comprehensive classification of the leptomeningeal surface receptors directly binding meningococcal ligands is lacking, but can be generated hypothetically from what is known currently of bacterial ligand interactions with other cell types and the nature of receptors identified on leptomeninges and meningioma cells (Table 2).

The OM of CPS-null meningococci has been shown to interact intimately with the meningioma cell plasmalemma, inducing significant cell surface activation and membrane ruffling, that are not observed following the binding of capsulated meningococci [39]. It is likely that exposed OM
(SAS) of the sulcus. Cortex is labelled on one side of the sulcus and pia is indicated by an arrow on the other side of the sulcus. N. meningitidis do not adhere to the cortical brain tissue. c Adherence of $N$. meningitidis (yellow-green) to meningothelial meningioma cells (red) in culture. a, b Fluorescence microscopy scale bar $300 \mu \mathrm{m}$. c Confocal microscopy: scale bar $20 \mu \mathrm{m}$ a-c Published with permission from Ref. [39]

adhesin-invasins such as the Opa and Opc proteins mediate these interactions, which occur also on endothelial and epithelial cells. However, the meningeal cell receptors involved have not been confirmed. Despite these membrane rearrangements, meningococci do not invade meningioma cells and classical membrane-bound intracellular vacuoles containing bacteria are not observed [39]. Since bacteria and the inflammatory response are contained within the SAS, with little involvement of the underlying brain, this suggests that an intact pia is a considerable barrier to penetration of meningococci into the brain. Nonetheless, latestage and fatal meningitis is characterised by considerable death of leptomeningeal cells, thus presenting bacteria with the opportunity to interact with collagen underlying the pia and with astrocytes of the glia limitans superficialis and to potentially activate microglia.

\section{Leptomeningitis}

After entry into the CSF, leptomeningitis is established as a consequence of bacterial growth without immune restriction in the SAS and the direct interactions of meningococci with microvascular endothelial cells, the leptomeninges (with little involvement of the dura) and sentinel macrophages. LOS is the major component of meningococci that induces leptomeningitis [12], via binding to CD14-Toll-like receptor 
(TLR)4-MD2 on endothelial cells, macrophages and infiltrating PMNLs. Such interactions activate cell signalling pathways to induce the inflammatory response. By contrast, cytokine release by meningeal cells can occur independently of LOS-CD14/TLR4/MD2 interactions or the involvement of other host accessory proteins such as HSP70, HSP90 $\alpha$, CXCR4 or GDF5 [43]. Leptomeningitis is an 'inflammatory soup' of host response molecules [21] to invading meningococci and infection is characterised by the rapid infiltration of PMNLs. Neutrophils with intracellular bacteria have been observed in the CSF of patients, suggesting that this organism can survive and replicate within these cells [25]. Infiltrating PMNL augment the inflammatory response, and leptomeningitis serves to limit bacterial spread but at the expense of the host, leading to gross cell and tissue necrosis within the SAS. Untreated meningococcal leptomeningitis is invariably fatal and for survivors, permanent neurological sequelae are common.

\section{Conclusions}

This review has emphasised the key roles that leptomeningeal cells, in their many and diverse forms, play as barriers and facilitators for the movement of fluid, solutes, cells and bacteria in relation to the CNS. In foetal development the establishment of the arachnoid barrier complements the formation of the blood-brain barrier thus isolating the CSF and developing CNS from peripheral tissues that lack vascular barriers. Such isolation appears to be essential for ensuring appropriate morphogenic signalling within the CNS which is concentration-dependent and in which the arachnoid may play a part. The arachnoid barrier is retained in the adult brain and is prominent in containing CSF within the subarachnoid space and isolating the CSF from the dura. Leptomeninges also play many other subtle roles as summarised in Fig. 6, ranging from separation of connective tissue from the CSF to lining channels for the movement of CSF within the brain and drainage of CSF via arachnoid granulations and lymphatic pathways. Within the cranial and spinal SAS, leptomeninges appear to regulate patterns of flow for CSF and are sites for attachment of inflammatory cells which may facilitate their immunological and anti-microbial activities. Bacteria and tumour cells enter the CSF and attach to leptomeninges by mechanisms that may involve molecular mimicry and hijacking some of the attachment mechanisms used by inflammatory cells. Understanding such mechanisms has a potential role for the future management of leptomeningitis, autoimmune disorders of the CNS and tumour metastases in the CSF.

Acknowledgements ROC thanks Professor Ajay Verma and Biogen for supporting the studies of the canine brain. KM was supported by a grant from Vera and Carl Johan Michaelsen Foundation (Grant number 34077).

\section{Compliance with ethical standards}

Conflict of interest The authors have no conflicts of interest to declare.

Open Access This article is distributed under the terms of the Creative Commons Attribution 4.0 International License (http://creativecomm ons.org/licenses/by/4.0/), which permits unrestricted use, distribution, and reproduction in any medium, provided you give appropriate credit to the original author(s) and the source, provide a link to the Creative Commons license, and indicate if changes were made.

\section{References}

1. Abbott NJ, Patabendige AA, Dolman DE, Yusof SR, Begley DJ (2010) Structure and function of the blood-brain barrier. Neurobiol Dis 37:13-25

2. Abbott NJ, Pizzo ME, Preston JE, Janigro D, Thorne RG (2018) The role of brain barriers in fluid movement in the CNS - is there a "glymphatic" system? Acta Neuropathol (in press)

3. Alcolado JC, Moore IE, Weller RO (1986) Calcification in the human choroid plexus, meningiomas and pineal gland. Neuropathol Appl Neurobiol 12:235-250

4. Alcolado R, Weller RO, Parrish EP, Garrod D (1988) The cranial arachnoid and pia mater in man: anatomical and ultrastructural observations. Neuropathol Appl Neurobiol 14:1-17

5. Alkuwaity K, Taylor A, Heckels JE, Doran KS, Christodoulides M (2012) Group B Streptococcus interactions with human meningeal cells and astrocytes in vitro. PLoS ONE 7:e42660. https://doi.org/10.1371/journal.pone.0042660

6. Angelov DN, Vasilev VA (1989) Morphogenesis of rat cranial meninges. A light- and electron-microscopic study. Cell Tissue Res 257:207-216

7. Arbel-Ornath M, Hudry E, Eikermann-Haerter K, Hou S, Gregory JL, Zhao L, Betensky RA, Frosch MP, Greenberg SM, Bacskai BJ (2013) Interstitial fluid drainage is impaired in ischemic stroke and Alzheimer's disease mouse models. Acta Neuropatholol 126:353-364. https://doi.org/10.1007/s00401-013-1145-2

8. Aspelund A, Antila S, Proulx ST, Karlsen TV, Karaman S, Detmar M, Wiig H, Alitalo K (2015) A dural lymphatic vascular system that drains brain interstitial fluid and macromolecules. $\mathrm{J}$ Exp Med 212:991-999. https://doi.org/10.1084/jem.20142290

9. Auger JP, Christodoulides M, Segura M, Xu J, Gottschalk M (2015) Interactions of Streptococcus suis serotype 2 with human meningeal cells and astrocytes. BMC Res Notes 8:607

10. Balslev Y, Saunders NR, Møllgård K (1997) Ontogenetic development of diffusional restriction to protein at the pial surface of the rat brain: an electron microscopical study. J Neurocytol 26:133-148

11. Bhogal P, Makalanda HL, Brouwer PA, Gontu V, Rodesch G, Mercier P, Soderman M (2015) Normal pio-dural arterial connections. Interv Neuroradiol 21:750-758. https://doi.org/10.1177 /1591019915609137

12. Brandtzaeg P, van Deuren M (2012) Classification and pathogenesis of meningococcal infections. In: Christodoulides M (ed) Neisseria meningitidis: advanced methods and protocols. Methods in molecular biology, vol 799. Humana, New York, pp 21-35 
13. Brightman MW, Reese TS (1969) Junctions between intimately apposed cell membranes in the vertebrate brain. J Cell Biol 40:648-677

14. Brøchner CB, Holst CB, Møllgård K (2015) Outer brain barriers in rat and human development. Front Neurosci 9:75

15. Brocklehurst G (1969) The development of the human cerebrospinal fluid pathway with particular reference to the roof of the fourth ventricle. J Anat 105:467-475

16. Carare RO (2017) Editorial: clearance pathways for amyloidbeta. Significance for Alzheimer's disease and its therapy. Front Aging Neurosci 9:339. https://doi.org/10.3389/fnag i.2017.00339

17. Carare RO, Bernardes-Silva M, Newman TA, Page AM, Nicoll JA, Perry VH, Weller RO (2008) Solutes, but not cells, drain from the brain parenchyma along basement membranes of capillaries and arteries: significance for cerebral amyloid angiopathy and neuroimmunology. Neuropathol Appl Neurobiol 34:131-144. https://doi.org/10.1111/j.1365-2990.2007.0092 6.x

18. Carare RO, Hawkes CA, Jeffrey M, Kalaria RN, Weller RO (2013) Review: cerebral amyloid angiopathy, prion angiopathy, CADASIL and the spectrum of protein elimination failure angiopathies (PEFA) in neurodegenerative disease with a focus on therapy. Neuropathol Appl Neurobiol 39:593-611. https://doi. org/10.1111/nan.12042

19. Charidimou A, Hong YT, Jager HR, Fox Z, Aigbirhio FI, Fryer TD, Menon DK, Warburton EA, Werring DJ, Baron JC (2015) White matter perivascular spaces on magnetic resonance imaging: marker of cerebrovascular amyloid burden? Stroke J Cereb Circul 46:1707-1709. https://doi.org/10.1161/STROKEAH A.115.009090

20. Christodoulides M (2013) A history of bacterial meningitis from antiquity to modern times. In: Christodoulides M (ed) Meningitis: cellular and molecular basis. Advances in molecular and cellular microbiology, vol 26. CABI, Wallingford, pp 1-16

21. Christodoulides M (2013) Inflammation in the subarachnoid space. In: Christodoulides M (ed) Meningitis: cellular and molecular basis. CABI, Wallingford

22. Clancy B, Darlington RB, Finlay BL (2001) Translating developmental time across mammalian species. Neuroscience 105:7-17

23. Coles JA, Stewart-Hutchinson PJ, Myburgh E, Brewer JM (2017) The mouse cortical meninges are the site of immune responses to many different pathogens, and are accessible to intravital imaging. Methods 127:53-61. https://doi.org/10.1016/j.ymeth.2017 .03 .020

24. Coureuil M, Lecuyer H, Bourdoulous S, Nassif X (2017) A journey into the brain: insight into how bacterial pathogens cross blood-brain barriers. Nat Rev Microbiol 15:149-159

25. Criss AK, Seifert HS (2012) A bacterial siren song: intimate interactions between Neisseria and neutrophils. Nat Rev Microbiol 10:178-190

26. Criswell TP, Sharp MM, Dobson H, Finucane C, Weller RO, Verma A, Carare RO (2017) The structure of the perivascular compartment in the old canine brain: a case study. Clin Sci (Lond) 131:2737-2744. https://doi.org/10.1042/CS20171278

27. Decimo I, Fumagalli G, Berton V, Krampera M, Bifari F (2012) Meninges: from protective membrane to stem cell niche. Am J Stem Cells 1:92-105

28. Djukic M, Trimmel R, Nagel I, Spreer A, Lange P, Stadelmann C, Nau R (2017) Cerebrospinal fluid abnormalities in meningeosis neoplastica: a retrospective 12-year analysis. Fluids Barriers CNS 14:7

29. Edwards VL, Wang LC, Dawson V, Stein DC, Song W (2013) Neisseria gonorrhoeae breaches the apical junction of polarized epithelial cells for transmigration by activating EGFR. Cell Microbiol 15:1042-1057
30. Engelhardt B, Carare RO, Bechmann I, Flugel A, Laman JD, Weller RO (2016) Vascular, glial, and lymphatic immune gateways of the central nervous system. Acta Neuropathol 132:317338. https://doi.org/10.1007/s00401-016-1606-5

31. Engelhardt B, Vajkoczy P, Weller RO (2017) The movers and shapers in immune privilege of the CNS. Nat Immunol 18:123131. https://doi.org/10.1038/ni.3666

32. Feurer DJ, Weller RO (1991) Barrier functions of the leptomeninges: a study of normal meninges and meningiomas in tissue culture. Neuropathol Appl Neurobiol 17:391-405

33. Fiorilli P, Partridge D, Staniszewska I, Wang JY, Grabacka M, So K, Marcinkiewicz C, Reiss K, Khalili K, Croul SE (2008) Integrins mediate adhesion of medulloblastoma cells to tenascin and activate pathways associated with survival and proliferation. Lab Invest 88:1143-1156

34. Fowler MI, Weller RO, Heckels JE, Christodoulides M (2004) Different meningitis-causing bacteria induce distinct inflammatory responses on interaction with cells of the human meninges. Cell Microbiol 6:555-567. https://doi.org/10.1111/j.1462-5822 2004.00382.x

35. Giuntini S, Pajon R, Ram S, Granoff DM (2015) Binding of complement factor $\mathrm{H}$ to PorB3 and NspA enhances resistance of Neisseria meningitidis to anti-factor $\mathrm{H}$ binding protein bactericidal activity. Infect Immun 83:1536-1545

36. Gomez DG, DiBenedetto AT, Pavese AM, Firpo A, Hershan DB, Potts DG (1982) Development of arachnoid villi and granulations in man. Acta Anat (Basel) 111:247-258

37. Graeber MB, Streit WJ, Kiefer R, Schoen SW, Kreutzberg GW (1990) New expression of myelomonocytic antigens by microglia and perivascular cells following lethal motor neuron injury. $\mathrm{J}$ Neuroimmunol 27:121-132

38. Hansen TP, Cain J, Thomas O, Jackson A (2015) Dilated perivascular spaces in the Basal Ganglia are a biomarker of small-vessel disease in a very elderly population with dementia. Am J Neuroradiol 36:893-898

39. Hardy SJ, Christodoulides M, Weller RO, Heckels JE (2000) Interactions of Neisseria meningitidis with cells of the human meninges. Mol Microbiol 36:817-829

40. Hawkes CA, Hartig W, Kacza J, Schliebs R, Weller RO, Nicoll JA, Carare RO (2011) Perivascular drainage of solutes is impaired in the ageing mouse brain and in the presence of cerebral amyloid angiopathy. Acta Neuropathol 121:431-443. http s://doi.org/10.1007/s00401-011-0801-7

41. Helaine S, Carbonnelle E, Prouvensier L, Beretti JL, Nassif X, Pelicic V (2005) PilX, a pilus-associated protein essential for bacterial aggregation, is a key to pilus-facilitated attachment of Neisseria meningitidis to human cells. Mol Microbiol 55:65-77

42. Hill DJ, Griffiths NJ, Borodina E, Virji M (2010) Cellular and molecular biology of Neisseria meningitidis colonization and invasive disease. Clin Sci (London, England: 1979) 118:547564. https://doi.org/10.1042/cs20090513

43. Humphries HE, Triantafilou M, Makepeace BL, Heckels JE, Triantafilou K, Christodoulides M (2005) Activation of human meningeal cells is modulated by lipopolysaccharide (LPS) and non-LPS components of Neisseria meningitidis and is independent of Toll-like receptor (TLR)4 and TLR2 signalling. Cell Microbiol 7:415-430

44. Hung MC, Heckels JE, Christodoulides M (2013) The adhesin complex protein (ACP) of Neisseria meningitidis is a new adhesin with vaccine potential. MBio. https://doi.org/10.1128/ mBio.00041-13

45. Hutchings M, Weller RO (1986) Anatomical relationships of the pia mater to cerebral blood vessels in man. J Neurosurg 65:316325. https://doi.org/10.3171/jns.1986.65.3.0316

46. Iliff JJ, Wang M, Liao Y, Plogg BA, Peng W, Gundersen GA, Benveniste H, Vates GE, Deane R, Goldman SA, Nagelhus EA, 
Nedergaard M (2012) A paravascular pathway facilitates CSF flow through the brain parenchyma and the clearance of interstitial solutes, including amyloid beta. Sci Transl Med 4:147ra111. https://doi.org/10.1126/scitranslmed.3003748

47. Jarva H, Ram S, Vogel U, Blom AM, Meri S (2005) Binding of the complement inhibitor C4 bp to serogroup B Neisseria meningitidis. J Immunol 174:6299-6307

48. Jen FE, Warren MJ, Schulz BL, Power PM, Swords WE, Weiser JN, Apicella MA, Edwards JL, Jennings MP (2013) Dual pili post-translational modifications synergize to mediate meningococcal adherence to platelet activating factor receptor on human airway cells. PLoS Pathog 9:e1003377. https://doi. org/10.1371/journal.ppat.1003377

49. Johansson PA, Dziegielewska KM, Liddelow SA, Saunders NR (2008) The blood-CSF barrier explained: when development is not immaturity. BioEssays News Rev Mol Cell Dev Biol 30:237-248. https://doi.org/10.1002/bies.20718

50. Kadhim HJ, Gadisseux JF, Evrard P (1998) Topographical and cytological evolution of the glial phase during prenatal development of the human brain: histochemical and electron microscopic study. J Neuropathol Exp Neurol 47:166-188

51. Kallstrom H, Liszewski MK, Atkinson JP, Jonsson AB (1997) Membrane cofactor protein (MCP or CD46) is a cellular pilus receptor for pathogenic Neisseria. Mol Microbiol 25:639-647

52. Keable A, Fenna K, Yuen HM, Johnston DA, Smyth NR, Smith C, Al-Shahi Salman R, Samarasekera N, Nicoll JA, Attems J, Kalaria RN, Weller RO, Carare RO (2016) Deposition of amyloid beta in the walls of human leptomeningeal arteries in relation to perivascular drainage pathways in cerebral amyloid angiopathy. Biochem Biophys Acta 1862:1037-1046. https:// doi.org/10.1016/j.bbadis.2015.08.024

53. Khairalla AS, Omer SA, Mahdavi J, Aslam A, Dufailu OA, Self T, Jonsson AB, Georg M, Sjolinder H, Royer PJ, MartinezPomares L, Ghaemmaghami AM, Wooldridge KG, Oldfield NJ, Ala'Aldeen DA (2015) Nuclear trafficking, histone cleavage and induction of apoptosis by the meningococcal App and MspA autotransporters. Cell Microbiol 17:1008-1020

54. Kida S, Pantazis A, Weller RO (1993) CSF drains directly from the subarachnoid space into nasal lymphatics in the rat. Anatomy, histology and immunological significance. Neuropathol Appl Neurobiol 19:480-488

55. Kida S, Weller RO (1993) Morphological basis for fluid transport through and around ependymal, arachnoidal and glial cells. In: Raimondi AJ (ed) Intracranial cyst lesions. Springer, New York, pp 37-52

56. Kida S, Yamashima T, Kubota T, Ito H, Yamamoto S (1988) A light and electron microscopic and immunohistochemical study of human arachnoid villi. J Neurosurg 69:429-435

57. Krahn V (1981) Leukodiapedesis and leukocyte migration in the leptomeninges and in the subarachnoid space. J Neurol 226:43-52

58. Lappann M, Danhof S, Guenther F, Olivares-Florez S, Mordhorst IL, Vogel U (2013) In vitro resistance mechanisms of Neisseria meningitidis against neutrophil extracellular traps. Mol Microbiol 89:433-449

59. Louveau A, Smirnov I, Keyes TJ, Eccles JD, Rouhani SJ, Peske JD, Derecki NC, Castle D, Mandell JW, Lee KS, Harris TH, Kipnis J (2015) Structural and functional features of central nervous system lymphatic vessels. Nature 523:337-341. http s://doi.org/10.1038/nature14432

60. Mandrell RE, Griffiss JM, Macher BA (1988) Lipooligosaccharides (LOS) of Neisseria gonorrhoeae and Neisseria meningitidis have components that are immunochemically similar to precursors of human blood group antigens. Carbohydratesequence specificity of the mouse monoclonal antibodies that recognize crossreacting antigens on LOS andhuman erythrocytes. J Exp Med 168(1):107-126

61. Mollanji R, Papaiconomou C, Boulton M, Midha R, Johnston $M$ (2001) Comparison of cerebrospinal fluid transport in fetal and adult sheep. Am J Physiol Regul Integr Comp Physiol 281:R1215-R1223. https://doi.org/10.1152/ajpregu.2001 .281.4.R1215

62. Møllgård K, Dziegielewska KM, Holst CB, Habgood MD, Saunders NR (2017) Brain barriers and functional interfaces with sequential appearance of $\mathrm{ABC}$ efflux transporters during human development. Sci Rep 7:11603. https://doi.org/10.1038 /s41598-017-11596-0

63. Morita K, Sasaki H, Fujimoto K, Furuse M, Tsukita S (1999) Claudin-11/OSP-based tight junctions of myelin sheaths in brain and Sertoli cells in testis. J Cell Biol 145:579-588

64. Morris AW, Sharp MM, Albargothy NJ, Fernandes R, Hawkes CA, Verma A, Weller RO, Carare RO (2016) Vascular basement membranes as pathways for the passage of fluid into and out of the brain. Acta Neuropathol 131:725-736. https://doi. org/10.1007/s00401-016-1555-z

65. Nabeshima S, Reese TS, Landis DM, Brightman MW (1975) Junctions in the meninges and marginal glia. J Comp Neurol 164:127-169

66. Nagele V, Heesemann J, Schielke S, Jimenez-Soto LF, Kurzai O, Ackermann N (2011) Neisseria meningitidis adhesin NadA targets beta1 integrins: functional similarity to Yersinia invasin. J Biol Chem 286:20536-20546

67. Neumann JE, Swartling FJ, Schuller U (2017) Medulloblastoma: experimental models and reality. Acta Neuropathol 134:679-689. https://doi.org/10.1007/s00401-017-1753-3

68. Nicholas DS, Weller RO (1988) The fine anatomy of the human spinal meninges. A light and scanning electron microscopy study. J Neurosurg 69:276-282. https://doi.org/10.3171/jns.1988 .69.2.0276

69. Northcott PA, Buchhalter I, Morrissy AS et al (2017) The whole-genome landscape of medulloblastoma subtypes. Nature 547:311-317

70. O'Rahilly R, Muller F (1986) The meninges in human development. J Neuropathol Exp Neurolol 45:588-608

71. O'Rahilly R, Muller F (2010) Developmental stages in human embryos: revised and new measurements. Cells Tissues Organs 192:73-84

72. Oldfield NJ, Bland SJ, Taraktsoglou M, Dos Ramos FJ, Robinson K, Wooldridge KG, Ala'Aldeen DA (2007) T-cell stimulating protein A (TspA) of Neisseria meningitidis is required for optimal adhesion to human cells. Cell Microbiol 9:463-478

73. Orihuela CJ, Mahdavi J, Thornton J, Mann B, Wooldridge KG, Abouseada N, Oldfield NJ, Self T, Ala'Aldeen DA, Tuomanen EI (2009) Laminin receptor initiates bacterial contact with the blood brain barrier in experimental meningitis models. J Clin Invest 119:1638-1646

74. Pluddemann A, Mukhopadhyay S, Sankala M, Savino S, Pizza M, Rappuoli R, Tryggvason K, Gordon S (2009) SR-A, MARCO and TLRs differentially recognise selected surface proteins from Neisseria meningitidis: an example of fine specificity in microbial ligand recognition by innate immune receptors. J Innate Immun 1:153-163

75. Pollock H, Hutchings M, Weller RO, Zhang ET (1997) Perivascular spaces in the basal ganglia of the human brain: their relationship to lacunes. J Anat 191(Pt 3):337-346

76. Pron B, Taha MK, Rambaud C, Fournet JC, Pattey N, Monnet JP, Musilek M, Beretti JL, Nassif X (1997) Interaction of Neisseria meningitidis with the components of the blood-brain barrier correlates with an increased expression of PilC. J Infect Dis 176:1285-1292 
77. Ramaswamy V, Taylor MD (2017) Medulloblastoma: from myth to molecular. J Clin Oncol 35:2355-2363

78. Reboldi A, Coisne C, Baumjohann D, Benvenuto F, Bottinelli D, Lira S, Uccelli A, Lanzavecchia A, Engelhardt B, Sallusto F (2009) C-C chemokine receptor 6-regulated entry of TH-17 cells into the CNS through the choroid plexus is required for the initiation of EAE. Nat Immunol 10:514-523. https://doi.org/10.1038/ ni. 1716

79. Roher AE, Kuo YM, Esh C, Knebel C, Weiss N, Kalback W, Luehrs DC, Childress JL, Beach TG, Weller RO, Kokjohn TA (2003) Cortical and leptomeningeal cerebrovascular amyloid and white matter pathology in Alzheimer's disease. Mol Med 9:112-122

80. Salzman KL, Osborn AG, House P, Jinkins JR, Ditchfield A, Cooper JA, Weller RO (2005) Giant tumefactive perivascular spaces. AJNR 26:298-305

81. Sapsford I, Buontempo J, Weller RO (1983) Basement membrane surfaces and perivascular compartments in normal human brain and glial tumours. A scanning electron microscope study. Neuropathol Appl Neurobiol 9:181-194

82. Sato K, Shimizu K, Fujimura M, Inoue T, Matsumoto Y, Tominaga $\mathrm{T}$ (2011) Compromise of brain tissue caused by cortical venous reflux of intracranial dural arteriovenous fistulas assessment with diffusion-weighted magnetic resonance imaging. Stroke J Cereb Circ 42:998-1003

83. Saunders NR, Habgood MD, Møllgård K, Dziegielewska KM (2016) The biological significance of brain barrier mechanisms: help or hindrance in drug delivery to the central nervous system. F1000Res. https://doi.org/10.12688/f1000research.7378.1

84. Scarselli M, Serruto D, Montanari P, Capecchi B, Adu-Bobie J, Veggi D, Rappuoli R, Pizza M, Arico B (2006) Neisseria meningitidis NhhA is a multifunctional trimeric autotransporter adhesin. Mol Microbiol 61:631-644

85. Schlager C, Korner H, Krueger M, Vidoli S, Haberl M, Mielke D, Brylla E, Issekutz T, Cabanas C, Nelson PJ, Ziemssen T, Rohde V, Bechmann I, Lodygin D, Odoardi F, Flugel A (2016) Effector T-cell trafficking between the leptomeninges and the cerebrospinal fluid. Nature 530:349-353. https://doi.org/10.1038/nature16 939

86. Schmechel DE, Rakic P (1979) A Golgi study of radial glial cells in developing monkey telencephalon: morphogenesis and transformation into astrocytes. Anat Embryol (Berl) 156:115-152

87. Schubert-Unkmeir A, Konrad C, Slanina H, Czapek F, Hebling S, Frosch M (2010) Neisseria meningitidis induces brain microvascular endothelial cell detachment from the matrix and cleavage of occludin: a role for MMP-8. PLoS Pathog 6:e1000874. http s://doi.org/10.1371/journal.ppat.1000874

88. Seib KL, Scarselli M, Comanducci M, Toneatto D, Masignani V (2015) Neisseria meningitidis factor H-binding protein fHbp: a key virulence factor and vaccine antigen. Expert Rev Vaccines 14:841-859

89. Siegenthaler JA, Pleasure SJ (2011) We have got you 'covered': how the meninges control brain development. Curr Opin Genet Dev 21:249-255

90. Slanina H, Mundlein S, Hebling S, Schubert-Unkmeir A (2014) Role of epidermal growth factor receptor signaling in the interaction of Neisseria meningitidis with endothelial cells. Infect Immun 82:1243-1255

91. Smith AJ, Verkman AS (2017) The "glymphatic" mechanism for solute clearance in Alzheimer's disease: game changer or unproven speculation? FASEB J. https://doi.org/10.1096/fj.2017 00999

92. Soderholm N, Vielfort K, Hultenby K, Aro H (2011) Pathogenic Neisseria hitchhike on the uropod of human neutrophils. PLoS One 6:e24353. https://doi.org/10.1371/journal.pone.0024353
93. Stolp HB, Liddelow SA, Sa-Pereira I, Dziegielewska KM, Saunders NR (2013) Immune responses at brain barriers and implications for brain development and neurological function in later life. Front Integr Neurosci 7:61. https://doi.org/10.3389/fnin t.2013.00061

94. Szentistvanyi I, Patlak CS, Ellis RA, Cserr HF (1984) Drainage of interstitial fluid from different regions of rat brain. Am J Physiol 246:F835-F844

95. Toikka J, Aalto J, Hayrinen J, Pelliniemi LJ, Finne J (1998) The polysialic acid units of the neural cell adhesion molecule N-CAM form filament bundle networks. J Biol Chem 273:28557-28559

96. Toussi DN, Wetzler LM, Liu X, Massari P (2016) Neisseriae internalization by epithelial cells is enhanced by TLR2 stimulation. Microbes Infect Institut Pasteur 18:627-638. https://doi. org/10.1016/j.micinf.2016.06.001

97. Tripathi BJ, Tripathi RC (1974) Vacuolar transcellular channels as a drainage pathway for cerebrospinal fluid. J Physiol 239:195-206

98. Upton ML, Weller RO (1985) The morphology of cerebrospinal fluid drainage pathways in human arachnoid granulations. J Neurosurg 63:867-875. https://doi.org/10.3171/jns.1985.63.6.0867

99. Vacca I, Del Tordello E, Gasperini G, Pezzicoli A, Di Fede M, Rossi Paccani S, Marchi S, Mubaiwa TD, Hartley-Tassell LE, Jennings MP, Seib KL, Masignani V, Pizza M, Serruto D, Arico B, Delany I (2016) Neisserial heparin binding antigen (NHBA) contributes to the adhesion of Neisseria meningitidis to human epithelial cells. PLoS One 11:e0162878. https://doi.org/10.1371 /journal.pone.0162878

100. Verney C, Monier A, Fallet-Bianco C, Gressens P (2010) Early microglial colonization of the human forebrain and possible involvement in periventricular white-matter injury of preterm infants. J Anat 217:436-448

101. Voigt T (1989) Development of glial cells in the cerebral wall of ferrets: direct tracing of their transformation from radial glia into astrocytes. J Comp Neurol 289:74-88

102. Weller RO (1999) Reaction of intrathecal and epidural spaces to infection and inflammation. In: Yaksh TL (ed) Spinal drug delivery. Elsevier, Amsterdam, pp 297-315

103. Weller RO (2005) Microscopic morphology and histology of the human meninges. Morphologie 89:22-34

104. Weller RO, Hawkes CA, Kalaria RN, Werring DJ, Carare RO (2015) White matter changes in dementia: role of impaired drainage of interstitial fluid. Brain Pathol 25:63-78. https://doi. org/10.1111/bpa.12218

105. Whish S, Dziegielewska KM, Møllgård K, Noor NM, Liddelow SA, Habgood MD, Richardson SJ, Saunders NR (2015) The inner CSF-brain barrier: developmentally controlled access to the brain. Front Neurosci 9:16

106. Wisniewski HM, Wegiel J (1994) Beta-amyloid formation by myocytes of leptomeningeal vessels. Acta Neuropathol (Berl) $87: 233-241$

107. Wolburg H, Mack AF (2014) Comment on the topology of mammalian blood-cerebrospinal fluid barrier. Neurol Psych Brain Res 20:70-72

108. Yasuda K, Cline C, Vogel P, Onciu M, Fatima S, Sorrentino BP, Thirumaran RK, Ekins S, Urade Y, Fujimori K, Schuetz EG (2013) Drug transporters on arachnoid barrier cells contribute to the blood-cerebrospinal fluid barrier. Drug Metab Dispos 41:923-931

109. Zhang ET, Inman CB, Weller RO (1990) Interrelationships of the pia mater and the perivascular (Virchow-Robin) spaces in the human cerebrum. J Anat 170:111-123 